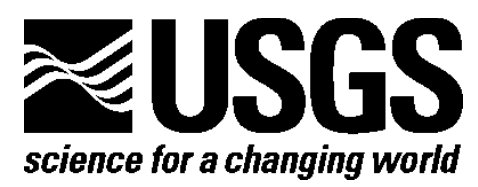

\title{
Three-Dimensional Ground-Motion Simulations of Earthquakes for the Hanford Area, Washington
}

By Arthur Frankel, Paul Thorne, and Alan Rohay

Open-File Report 2013-1289

U.S. Department of the Interior

U.S. Geological Survey 


\title{
U.S. Department of the Interior \\ SALLY JEWELL, Secretary
}

\section{U.S. Geological Survey \\ Suzette M. Kimball, Acting Director}

U.S. Geological Survey, Reston, Virginia: 2014

For more information on the USGS-the Federal source for science about the Earth, its natural and living resources, natural hazards, and the environment-visit http://www.usgs.gov or call 1-888-ASK-USGS

For an overview of USGS information products, including maps, imagery, and publications, visit $h$ ttp://www.usgs.gov/pubprod

To order this and other USGS information products, visit http://store.usgs.gov

\author{
Suggested citation: \\ Frankel, Arthur, Thorne, Paul, and Rohay, Alan, 2014, Three-dimensional ground-motion simulations of earthquakes \\ for the Hanford area, Washington: U.S. Geological Survey Open-File Report 2013-1289, 48 p., \\ http://dx.doi.org/10.3133/ofr20131289. \\ ISSN 2331-1258 (online)
}

Any use of trade, product, or firm names is for descriptive purposes only and does not imply endorsement by the U.S. Government.

Although this report is in the public domain, permission must be secured from the individual copyright owners to reproduce any copyrighted material contained within this report. 


\section{Contents}

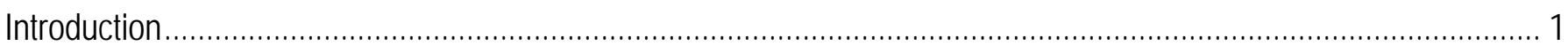

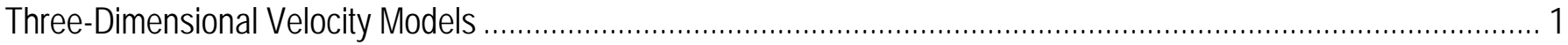

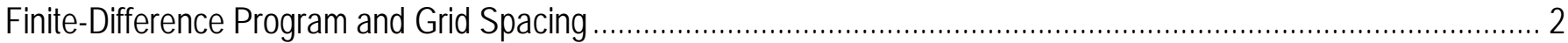

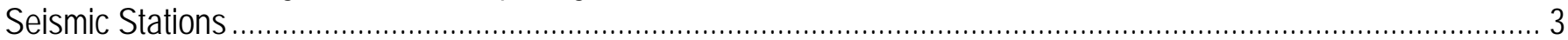

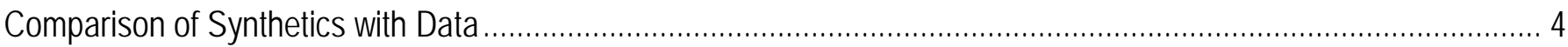

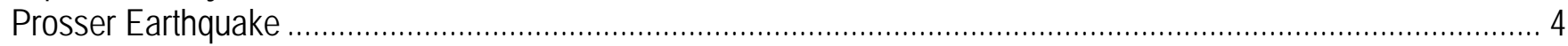

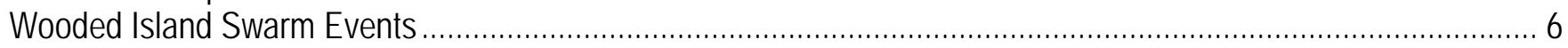

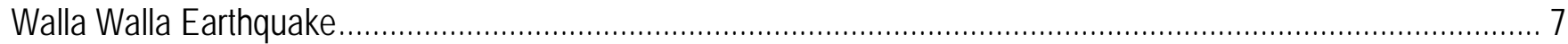

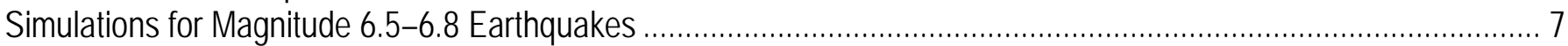

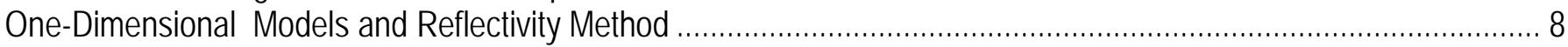

Rattlesnake Hills Fault, West, Moment Magnitude 6.8............................................................................ 9

Rattlesnake Hills Fault, East, Moment Magnitude 6.7 ..............................................................................

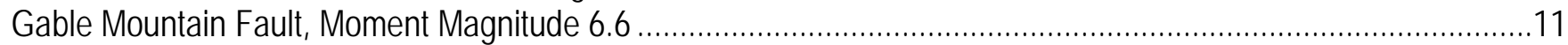

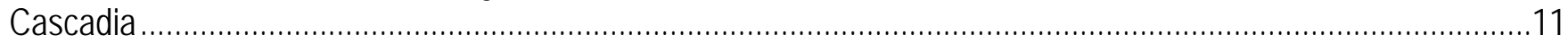

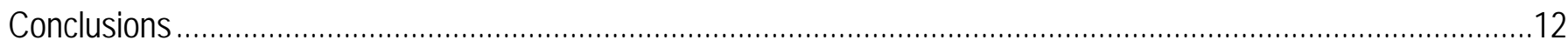

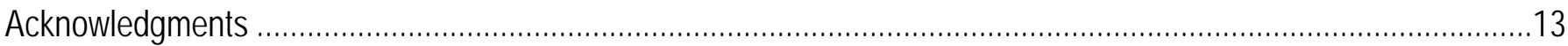

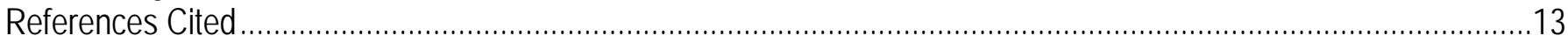

\section{Figures}

Figure 1. Map of depth (meters) to S-wave velocity (Vs) of 1,500 meters per second for the Hanford area,

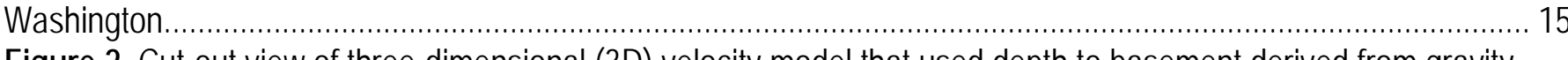

Figure 2. Cut-out view of three-dimensional (3D) velocity model that used depth to basement derived from gravityderived model (GDM)

Figure 3. 3D views of the elevation of the top of basement $(\mathrm{m})$ for the gravity-derived model (GDM; top) and the refraction-derived model (RDM; bottom.

Figure 4. Satellite image of Hanford area from GoogleEarth ${ }^{T M}$ showing locations of strong-motion accelerometers (circles), broadband stations (squares), and earthquakes studied (stars)

Figure 5. Observed (black) and synthetic (red) velocity waveforms at station H4A for the Prosser earthquake .......... 19

Figure 6. One-dimensional (1D) velocity profiles at station H2E used in the modeling of the recorded earthquakes.

The gravity-derived model (GDM) uses the depth to top of basement derived from gravity modeling........................ 20

Figure 7. Observed (black) and synthetic (red) velocity waveforms at station H4A for the Prosser earthquake ......... 21

Figure 8. Observed (black) and synthetic (red) velocity waveforms at station LTH for the Prosser earthquake ......... 22

Figure 9. Observed (black) and synthetic (red) velocity waveforms at station $\mathrm{H} 2 \mathrm{E}$ for the Prosser earthquake ......... 23

Figure 10. Observed (black) and synthetic (red) velocity waveforms at station H3A for the Prosser earthquake....... 24

Figure 11. Observed (black) and synthetic (red) velocity waveforms at station HAWA for the Prosser earthquake. .. 25

Figure 12. Observed and synthetics velocity waveforms (NS component) at station HAWA for the Prosser

earthquake

Figure 13. Bias and standard deviation of the spectral accelerations from the observed recordings at 0.5 and $1.0 \mathrm{~s}$ with respect to the spectral accelerations from the synthetics for the Prosser earthquakes (stations H3A, H4A, H2E,

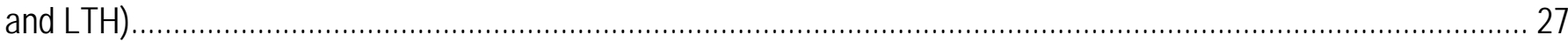

Figure 14. Bias and standard deviation of observed versus synthetic spectral accelerations for the Prosser earthquake.

Figure 15. Bias and standard deviation of observed versus synthetic spectral accelerations for the Prosser earthquake using three-dimensional (3D) models with different depths to basement 
Figure 16. Cumulative energy at station H4A for Prosser earthquake plotted with respect to time after origin time for observed seismograms (black and red lines) compared to synthetics (green and blue lines) from three-dimensional (3D) (top) and one-dimensional (1D) (bottom) velocity models

Figure 17. Bias and standard deviation of energy derived from observed seismograms compared with those from the three-dimensional (3D) and one-dimensional (1D) synthetics, for the Prosser earthquake (stations H3A, H4A, H2E, and LTH).

Figure 18. Observed (black) and synthetic (red) velocity waveforms for the September 2011 Wooded Island earthquake. 32

Figure 19. Bias and standard deviation of the observed and synthetics spectral accelerations for the September 2011 Wooded Island earthquake.

Figure 20. Observed (black) and synthetic (red) velocity waveforms for the October 2011

Wooded Island earthquake

Figure 21. Bias and standard deviation of the observed and synthetic spectral accelerations for the October 2011 Wooded Island earthquake

Figure 22. Observed (black) and synthetic (red) velocity waveforms at station LTH for the Walla Walla earthquake....

Figure 23. Map showing surficial S-wave velocity (Vs)(in meters per second) of three-dimensional model and surface projections (red rectangles) of rupture planes used in the simulations.

Figure 24. Final slip and rupture initiation times for one of the simulations for the Rattlesnake Hills West source. .... 38 Figure 25. S-wave velocity (Vs) profiles used in the one-dimensional (1D) simulations for the Rattlesnake Hills West and Gable Mountain sources (bottom panel shows shallow portion).

Figure 26. Velocity seismograms for one of the simulations of a magnitude 6.8 earthquake on the Rattlesnake Hills West source

Figure 27. Natural logarithms of ratios of spectral accelerations between the three-dimensional (3D) and onedimensional (1D) models for the magnitude 6.8 Rattlesnake Hills West source for the sites used for the probabilistic seismic hazard assessment.

Figure 28. Velocity seismograms for one of the simulations of a M6.7 earthquake on the Rattlesnake Hills East source.

Figure 29. Natural logarithms of ratios of spectral accelerations between the three-dimensional and one-dimensional models for the magnitude 6.7 Rattlesnake Hills East source for the sites used for the probabilistic seismic hazard assessment.

Figure 30. Velocity seismograms for one of the simulations of a magnitude 6.6 earthquake on the Gable Mountain fault. 44

Figure 31. Natural logarithms of ratios of spectral accelerations between the three-dimensional and one-dimensional models for the magnitude 6.6 Gable Mountain source for the sites used for the probabilistic seismic hazard assessment. 45

Figure 32. Velocity seismograms for simulation for Cascadia plane-wave source Synthetics for three-dimensional model are in black, synthetics for one-dimensional models are in red, and vertical scale is in arbitrary units. 46 Figure 33. Natural logarithms of ratios of spectral accelerations from the three-dimensional model relative to those from the one-dimensional model at each site for the Cascadia plane wave source.

\section{Table}

Table 1. Source parameters of earthquakes simulated in this study. 48 


\section{Conversion Factors and Datums}

\begin{tabular}{lll}
\multicolumn{1}{c}{ Sl to Inch/Pound } & & \\
\hline & Bultiply & \multicolumn{1}{c}{ To obtain } \\
\hline meter $(\mathrm{m})$ & 3.281 & foot $(\mathrm{ft})$ \\
kilometer $(\mathrm{km})$ & 0.6214 & mile (mi) \\
kilometer $(\mathrm{km})$ & 0.5400 & mile, nautical (nmi) \\
meter $(\mathrm{m})$ & 1.094 & yard $(\mathrm{yd})$ \\
\hline & Flow rate & \\
\hline meter per second $(\mathrm{m} / \mathrm{s})$ & 3.281 & foot per second $(\mathrm{ft} / \mathrm{s})$ \\
\hline
\end{tabular}

Temperature in degrees Celsius $\left({ }^{\circ} \mathrm{C}\right)$ may be converted to degrees Fahrenheit $\left({ }^{\circ} \mathrm{F}\right)$ as follows:

${ }^{\circ} \mathrm{F}=\left(1.8 \times{ }^{\circ} \mathrm{C}\right)+32$

\section{Datums}

Vertical coordinate information is referenced to the North American Vertical Datum of 1988 (NAVD 88)

Horizontal coordinate information is referenced to the North American Datum of 1983 (NAD 83)

Altitude, as used in this report, refers to distance above the vertical datum. 
This page left intentionally blank 


\title{
Three-Dimensional Ground-Motion Simulations of Earthquakes for the Hanford Area, Washington
}

\author{
By Arthur Frankel ${ }^{1}$, Paul Thorne², and Alan Rohay²
}

\section{Introduction}

This report describes the results of ground-motion simulations of earthquakes using three-dimensional (3D) and one-dimensional (1D) crustal models conducted for the probabilistic seismic hazard assessment (PSHA) of the Hanford facility, Washington, under the Senior Seismic Hazard Analysis Committee (SSHAC) guidelines. The first portion of this report demonstrates that the 3D seismic velocity model for the area produces synthetic seismograms with characteristics (spectral response values, duration) that better match those of the observed recordings of local earthquakes, compared to a $1 \mathrm{D}$ model with horizontal layers. The second part of the report compares the response spectra of synthetics from 3D and 1D models for moment magnitude (M) 6.6-6.8 earthquakes on three nearby faults and for a dipping plane wave source meant to approximate regional S-waves from a Cascadia great earthquake. The 1D models are specific to each site used for the PSHA. The use of the 3D model produces spectral response accelerations at periods of $0.5-2.0$ seconds as much as a factor of 4.5 greater than those from the 1D models for the crustal fault sources. The spectral accelerations of the 3D synthetics for the Cascadia plane-wave source are as much as a factor of 9 greater than those from the 1D models. The differences between the spectral accelerations for the 3D and 1D models are most pronounced for sites with thicker supra-basalt sediments and for earthquakes on the Rattlesnake Hills fault and for the Cascadia plane-wave source.

\section{Three-Dimensional Velocity Models}

Paul Thorne, Alan Rohay, and Stephen Reidel developed two 3D crustal models describing the P-wave velocity (Vp), S-wave velocity (Vs), and density for the Hanford area. The models were based on maps of thicknesses of the various geologic units in the area. Each geologic unit was assigned a Vp, Vs, and density. For the shallow units, these values were based on borehole velocity measurements. The parameters for the deeper layers were constrained from seismic refraction surveys and gravity data (for example, Burns and others, 2011).

\footnotetext{
${ }^{1}$ U.S. Geological Survey.

${ }^{2}$ Pacific Northwest National Laboratory.
} 
The shallow portion of the Hanford region is characterized by a relatively thin layer ( $<150 \mathrm{~m}$ ) of Holocene to Miocene sediments on top of a sequence of Columbia River basalts approximately 3-5 km thick. The depth to Vs of $1,500 \mathrm{~m} / \mathrm{s}$ for the model, which is equivalent to a map of the thickness of these supra-basalt sediments, is shown in figure 1 . There is a strong velocity contrast at the base of the surficial sediments and the top of the Columbia River basalts. As we will demonstrate from the observations and simulations, these supra-basalt sediments can be a waveguide for high-frequency (1-2 hertz [Hz]) surface waves and can produce reverberations of nearly vertically propagating $S$-waves. The supra-basalt sediments include Holocene deposits of alluvium and loess, Pleistocene flood deposits (Hanford Formation), PlioPleistocene deposits, and the Ringold Formation of Miocene-Pliocene age (Geomatrix, 1996). The minimum Vs is $425 \mathrm{~m} / \mathrm{s}$. There are several different basaltic units, including the Saddle Mountains, Wanapum, and Grand Ronde basalts. Each of these units was assigned a Vp, Vs, and density. The model did not explicitly include the thin interbedded layers of sediment within the basalts. The velocities and density of the Saddle Mountains basalt were adjusted to account for the sediment interbeds.

There is a large thickness of pre-Miocene sediments beneath the basalts, although substantial uncertainty exists about this thickness. Two models were produced. One was based on modeling of gravity data and had an inferred thickness of about 1-2 km for the sub-basalt sediments. This depth-to-basement model was provided by Stephen Reidel and is denoted as the gravity-derived model (GDM). A cut-out view of this model is shown in figure 2. The other model was based on seismic refraction data and the thicknesses of the sub-basalt sediments were about about 5-6 km (Glover, 1985). This model is called the refraction-derived model (RDM). The 3D configurations of the top of basement in the two models are shown in figure 3. There is a Vp and Vs gradient with depth within the sub-basalt sediments. The basement rock was assigned a Vp of 6,100 m/s and Vs of 3,500 m/s. The maximum depth of the model was $25 \mathrm{~km}$.

The finite-difference program used in this study requires a flat, free surface. The 3D models were developed so that the thicknesses of the supra-basalt sediments and the other geologic units at any location were preserved. In the 3D models, these thicknesses were applied starting at a free surface with a constant elevation.

Qs values were determined from Vs using the formulas from Frankel and others (2007, 2009), which were used in simulations for the Seattle basin and produced good fits to the observed spectral amplifications and waveforms. For Vs less than 1,000 m/s, Qs $=0.16428 * V s$ 14.2857, where Vs is in $\mathrm{m} / \mathrm{s}$. For Vs $>1,000 \mathrm{~m} / \mathrm{s}$, Qs $=0.15^{*} \mathrm{Vs}$. As will be shown later, these Qs values produce durations of synthetics similar to the data. Qp was taken to be $2 * \mathrm{Qs}$.

\section{Finite-Difference Program and Grid Spacing}

We used the 3D finite-difference computer program DISFD written by Pengcheng Liu of the Bureau of Reclamation (Liu and Archuleta, 2002). This program consists of a time-stepping algorithm to solve for the velocity vectors and stress tensors on a grid with complex material properties. The code uses fourth order finite-difference approximations for the partial derivatives in space and second order approximation for the partial derivative in time (Liu and Archuleta, 2002). A key advantage of the code is that it allows for the grid spacing in the top portion of the model to be one-third of that in the bottom portion of the model. This saves substantial computing time, because the finer grid spacing needed for accuracy in the lower velocity layers near the surface does not have to be continued to deeper depths. The finite-difference code also allows for an increase of the vertical grid spacing with depth. The code uses the linear velocity- 
stress equations with frequency-independent Qp and Qs that can vary with position. Each source is specified by a seismic moment, rise time, start time, focal mechanism, and location in the grid. The code uses the message-passing interface (MPI) protocol so that multiple processors can be used. A typical run involved 96 processors on the Hydra Cluster in Menlo Park, California.

For the top $500 \mathrm{~m}$ of the model, the horizontal and vertical grid spacing used in the finitedifference simulations was $25 \mathrm{~m}$. The seismic velocities and densities in the top $500 \mathrm{~m}$ of the model were specified with a horizontal grid spacing of $100 \mathrm{~m}$ and vertical grid spacing of $25 \mathrm{~m}$. The finite-difference code interpolated to a horizontal grid spacing of $25 \mathrm{~m}$. At depths greater than $500 \mathrm{~m}$, the vertical grid spacing increased to $75 \mathrm{~m}$. At depths from 500 to $6,500 \mathrm{~m}$, the model was developed with a horizontal grid spacing of $200 \mathrm{~m}$ and vertical grid spacing of $75 \mathrm{~m}$. At depths greater than $6,500 \mathrm{~m}$, the model was specified with a vertical grid spacing of $225 \mathrm{~m}$ and horizontal spacing of $400 \mathrm{~m}$. The finite-difference code interpolated to a horizontal grid spacing of $75 \mathrm{~m}$ at depths greater than $500 \mathrm{~m}$. The vertical grid spacing used by the finitedifference code for depths greater than $8,000 \mathrm{~m}$ was $225 \mathrm{~m}$.

The simulations are accurate up to $2 \mathrm{~Hz}$. At the $425 \mathrm{~m} / \mathrm{s}$ minimum Vs, $2 \mathrm{~Hz}$ corresponds to a wavelength of $213 \mathrm{~m}$, which is 8.5 grid spacings ( $25 \mathrm{~m}$ for the top $500 \mathrm{~m}$ ). For fourth order codes, a general guideline is that at least six grid points per wavelength are required for accuracy (Alford and others, 1974).

All synthetics and data in this study are low-pass filtered with a corner frequency of 2.0 $\mathrm{Hz}$. The observed seismograms from the accelerometers also are high-pass filtered at $0.5 \mathrm{~Hz}$, because of poor signal-to-noise less than $0.5 \mathrm{~Hz}$. This high-pass filtering did not significantly affect determinations of spectral accelerations at 0.5 and 1.0 s. Seismograms from the broadband sensors did not require high-pass filtering.

\section{Seismic Stations}

Stations and earthquakes modeled in this study are shown in figure 4 . The key stations are the five strong-motion accelerometers currently operated by the Pacific Northwest Seismic Network (PNSN) of the University of Washington and originally installed by the Pacific Northwest National Laboratory (PNNL). We also used recordings from the broadband instruments at station HAWA (U.S. National Seismic Network), station LTH, and two stations from the Earthscope Transportable Array. The data from the broadband instruments were obtained from the IRIS Data Management Center. The seismograms from these instruments were converted to ground velocity using the poles, zeroes, and gains listed in their instrument files. The data search was assisted by the database compiled by Adrian Rodriguez-Marek for the Hanford PSHA (A. Rodriguez-Marek, written comm., 2013). 


\section{Comparison of Synthetics with Data}

\section{Prosser Earthquake}

The PNSN earthquake database was systematically searched to identify earthquakes that were larger than duration magnitude $\left(\mathrm{M}_{\mathrm{d}}\right) 3.0$ that occurred within the 3D model; that were recorded by the strong-motion stations on the Hanford facility with adequate signal to noise ratios; and that had focal mechanisms determined by the PNSN. Only three earthquakes matched those criteria (see table 1). A fourth earthquake somewhat outside the 3D model near Walla Walla, Washington, which was recorded by station LTH in the basin, also was identified, but pre-dated the strong-motion instruments.

The Prosser earthquake of October 18, 2008, had a duration magnitude of 3.7 and a depth of about $20 \mathrm{~km}$ (PNSN). This earthquake is especially important because it was near the downdip portion of the Rattlesnake Hills fault. The deep depth of the earthquake also provides a good test on whether the southern edge of the supra-basalt sediments (northern edge of Rattlesnake Hills) generates surface waves from incident, upward-propagating S-waves.

We used the focal mechanism for this earthquake derived from Robert Herrmann using inversion of regional surface waves. This focal mechanism differed substantially from that determined by P-wave first motions by the PNSN. The moment magnitude, $\mathrm{M}_{\mathrm{w}}$, determined by Herrmann was 3.27. We applied the relocated hypocenter listed in the Rodriguez-Marek database, which had a depth of $18 \mathrm{~km}$.

A comparison of the velocity waveforms at station H4A for the data and the 3D simulation using the RDM is shown in figure 5 (left). Because of the high frequencies involved, we were not expecting to match the data "wiggle for wiggle." However, the synthetics for the north-south (NS) component match the observed S-wave arrival time, peak velocities, and long duration of substantial ground motions after the initial S-wave arrival. For the east-west (EW) and vertical components, the 3D synthetics capture some of the arrivals after the S-wave, but not all of them.

Two 1D, flat-layered velocity models were constructed based on the velocities at station H2E near the waste-treatment plant (fig. 6). This model has a thickness of supra-basalt sediments of $100 \mathrm{~m}$. The 1D models used the thickness of sub-basalt sediments from the GDM and RDM. For these 1D simulations for modeling the recorded earthquakes, we did not use a velocity gradient for the sub-basalt sediments, applying depth-averaged average velocities and density. This did not significantly affect the waveforms of the 1D synthetics. The 3D finite-difference code was run using these flat-layered models.

The synthetics for the 1D model clearly do not contain the large arrivals after the S-wave that are observed in the data in all three components (fig. 5). This applies to the 1D models using GDM and (RDM values for the top of basement. The 1D models produce very small surface waves, relative to the $S$-waves, because the epicentral distance is only slightly greater than the depth of the hypocenter. The main difference in the synthetics from the GDM and RDM 1D models is the predicted S-wave arrival time. However, this discrepancy between the observed and predicted arrival times from the 1D model is just the result of the difference of thickness of the sub-basalt sediments between stations H4A and H2E where the 1D models were derived. 
The waveforms from the 3D models using the different depths to basement are very similar. The observed waveforms at station H4A and the synthetics from the 3D models are shown in figure 7 . The synthetics from both 3D models reproduce the substantial arrivals for $10 \mathrm{~s}$ after the S-waves that are observed in the data. For subsequent figures in this report, we used the 3D model with the RDM values for the depth to top of basement, unless otherwise indicated.

The arrivals observed after the S-wave are likely to be surface waves created near the southern edge of the supra-basalt sediments from the conversion of incident S-waves. There are several pieces of evidence for this interpretation: (1) these arrivals show dispersion in the observed acceleration traces with the long-period energy arriving first in the wave train, (2) their arrival $5 \mathrm{~s}$ after the S-wave is consistent with their creation at the southern edge of the basin and the $500 \mathrm{~m} / \mathrm{s}$ group velocity expected for the Vs of the supra-basalt sediments, and (3) the 1D models show that the direct surface waves have very small amplitudes for this distance and source depth. These high-frequency surface waves are largely trapped in the supra-basalt sediments, even though the sediments are less than $100 \mathrm{~m}$ thick. The observed recordings at station LTH exhibits similar large arrivals after the initial S-wave, which are matched by the synthetics from the 3D model but not by those from the 1D models (fig. 8).

The observed recordings at station H2E show ringing with long durations of tens of seconds after the initial S-wave (fig. 9). The synthetics from the 3D model (RDM) match the peak amplitudes and capture some of the long-duration character of the observations. In contrast, the synthetics from the 1D model are smaller than the observed recordings and have virtually no amplitude after the initial S-wave. On the EW component, the 1D synthetics show a very small S-wave arrival, in contrast with the larger S-wave observed in the data and the long duration of motion. The 3D and 1D synthetics are similar at station H3A (fig. 10), because of the relatively thin supra-basalt sediments at this location. Both sets of synthetics do not contain the significant arrival observed about $2 \mathrm{~s}$ after the S-wave.

Station HAWA is located on rock and the data displays a simple S-wave for this station in contrast to the more complex, long-duration arrivals for stations located on the supra-basalt sediments. These simple waveforms at station HAWA are matched by the 3D and 1D models (fig. 11). A phase on the radial component that arrives between the P- and S-waves is shown in the seismograms in figure 12. The polarization and arrival time indicate that this arrival is an $\mathrm{S}$ to $\mathrm{P}$ conversion (SP phase) at the top of the basement. Synthetics using the GDM predict an SP arrival later than the observed arrival, indicating that the top of basement is deeper than in the GDM (fig. 12). The RDM produces a SP phase closer to the timing of the data, but the S-wave arrival is delayed relative to the data. This may indicate that the S-wave velocities in the RDM are too slow for the path from the hypocenter to station HAWA.

The synthetics from the 3D model have spectral accelerations closer to the observed accelerations, compared to the 1D synthetics. The bias and standard deviation of the natural logarithms of the response spectral accelerations (5 percent critical damping; pseudo-spectral accelerations) at 0.5 and $1.0 \mathrm{~s}$ for the observations relative to the synthetics are shown in figure 13. Here we considered the stations on the supra-basalt sediments: H2E, H3A, H4A, and LTH. The geometrical average of the spectral acceleration from the two horizontal components was used. The bias of the 3D synthetics is much lower than the bias from the 1D synthetics, indicating that the 3D synthetics better match the observed spectral accelerations than the $1 \mathrm{D}$ 
synthetics. The 1D synthetics substantially under predict the observed spectral accelerations at 0.5 and $1.0 \mathrm{~s}$ (positive bias indicates that the observed data have larger spectral accelerations than the synthetics). The standard deviations are somewhat smaller for the 3D synthetics relative to the $1 \mathrm{D}$ synthetics, illustrating that the 3D model produces a better fit to the observed variations of spectral accelerations between stations than the 1D model.

The focal mechanism makes a significant difference in the fits to the response spectra. The bias and standard deviation between the 3D synthetics made with the Herrmann focal mechanism and those from the PNSN focal mechanism, both using the same 3D model are shown in figure 14. For $1 \mathrm{~s}$ period, the Hermann focal mechanism produces a better fit to the observed variations of spectral accelerations between the stations, as shown by the lower standard deviation.

There is no significant difference in the fits to the data for the GDM and RDM of the depth to basement (3D models; fig. 15) for 0.4 and $1.0 \mathrm{~s}$. This reflects the idea that it is the suprabasalt sediments that form the waveguide for the surface waves and the deeper structure is relatively inconsequential.

The energy was calculated from summing the square of the ground velocity as a function of time. The cumulative energy of the observed data and synthetics at station H4A is shown in figure 16. For the NS component, the energy of the observed data and the 3D synthetics are similar. The EW synthetics in the 3D model underestimate the observed energy on that component. The synthetics from the 1D model severely under predict the observed energy for both components. This is not unexpected given the short duration of the 1D synthetics compared to the data.

The 3D synthetics better predict the total energy of the observed records than the $1 \mathrm{D}$ synthetics. The bias and standard deviation of the total energy for observed and synthetic waveforms at stations H3A, H4A, H2E, and LTH are shown in figure 17. The bias is much lower for the $3 \mathrm{D}$ synthetics than the $1 \mathrm{D}$ synthetics, again demonstrating that the 3D model better fits the characteristic of the observed recordings than the 1D model and that the 1D model under predicts the observed energy.

\section{Wooded Island Swarm Events}

Two earthquakes in the Wooded Island area were simulated using the 3D and 1D models. These earthquakes were very shallow (depths less than $2 \mathrm{~km}$ ). For both earthquakes, the 3D and 1D simulations used an $M_{w}$ of $M_{d}-0.4$, based on the $M_{w}$ to $M_{d}$ difference found for the Prosser earthquake. Herrmann did not determine focal mechanisms or moments for these earthquakes, so the PNSN first-motion focal mechanisms were applied.

The observed and synthetic waveforms at stations $\mathrm{H} 4 \mathrm{~A}, \mathrm{H} 2 \mathrm{E}$, and $\mathrm{H} 2 \mathrm{~W}$ for the September 2011 earthquake are shown in figure 18. At station H4A closer to the hypocenter, the 3D and 1D synthetics underestimate the observed duration after the S-wave arrival. The 3D synthetics for stations $\mathrm{H} 2 \mathrm{E}$ and $\mathrm{H} 2 \mathrm{~W}$ generally reproduce the long duration of the observed records, whereas the $1 \mathrm{D}$ synthetics do not (fig. 18). However, the 3D model overestimates the peak velocities at stations $\mathrm{H} 2 \mathrm{E}$ and $\mathrm{H} 2 \mathrm{~W}$. The 1D model also overestimates the peak velocities at these stations. The bias and standard deviation between the 0.5 and 1.0-s spectral accelerations from the synthetic and the observed data are similar between the $3 \mathrm{D}$ and $1 \mathrm{D}$ models (fig. 19). For this comparison, we used stations H3A, H4A, H2E, H2W, and H1K. Because of the shallow 
depths of these earthquakes, the waveforms may be affected by scattering from topography that is not contained in the 3D and 1D models. This scattering by topography may be especially important for stations near the hypocenter, which is located approximately beneath the bluffs along the Columbia River.

The results are similar for the October 2011 earthquake. The 3D and 1D models underestimate the ringing observed after the S-wave at station H4A, close to the epicenter (fig. 20). For stations $\mathrm{H} 2 \mathrm{E}$ and $\mathrm{H} 2 \mathrm{~W}$, the $3 \mathrm{D}$ synthetics capture the long duration of shaking of the observed recordings. The 1D synthetics have shorter durations of shaking than the observed recordings. The bias of the observed and synthetic accelerations at 0.5 and $1.0 \mathrm{~s}$ are similar for the 3D and 1D models (fig. 21). The standard deviation at $1.0 \mathrm{~s}$ is lower for the $1 \mathrm{D}$ model than the 3D model, indicating that the 1D model better fits the observed variations of spectral accelerations at $1.0 \mathrm{~s}$ for this earthquake.

\section{Walla Walla Earthquake}

The earthquake near Walla Walla, Washington, is somewhat outside of the area of the 3D model and was not recorded on the strong-motion instruments. However, the earthquake was recorded at station LTH. The 3D model was extended to the east and to the south by continuing the velocity model at the southern and eastern edges. Synthetics from the 3D model show that it contains substantial arrivals after the S-wave at station LTH (NS component), although these do not have as much duration as the arrivals in the observed data (fig. 22). The synthetics for the 1D model are much shorter duration than the observed data at station LTH.

\section{Simulations for Magnitude 6.5-6.8 Earthquakes}

Given the importance of 3D propagation effects in the observed data, it is critical to assess how the 3D model affects the spectral accelerations predicted for M6 earthquakes from nearby faults, compared to those from 1D models. Here, we considered three sources: M6.8 earthquakes on the western part of the Rattlesnake Hills fault, M6.7 earthquakes on the eastern part of the Rattlesnake Hills fault, and M6.6 earthquakes on the Gable Mountain fault. The surface projections of the rupture zones are shown in figure 23. The rupture zones for the Rattlesnake Hills fault dipped to the south at 55 degrees. Ruptures on the Gable Mountain fault dipped to the south at 70 degrees. In addition, a dipping plane source was studied to approximate the regional S-waves from an M8-9 earthquake on the Cascadia subduction zone. Synthetics were calculated at the five sites used for the PSHA (fig. 23): A (200 East area and adjacent to the Waste Treatment Plant), B (200 West area), C (Columbia Generating Station), D (100 BC area), and E (300 area).

The general methodology for generating the rupture history for the M6 earthquakes follows that developed by Frankel (2009) for the deterministic portion of the calculation. First, slip distributions were developed, characterized by random fields with a wavenumber $(k)$ spectrum proportional to $k^{-2}$ and a Gaussian probability distribution. The along-strike and downdip correlation distances for each magnitude were taken from the formulas of Mai and Beroza (2002). A $500 \mathrm{~m}$ sub-fault dimension was used, with the rupture plane extending from depths of 3 to $15 \mathrm{~km}$. One of the slip distributions used for the Rattlesnake Hills West rupture is shown in 
figure 24. This slip for each sub-fault was then converted into seismic moment, using the depthdependent Vs and density along the rupture plane from the 3D velocity model. The moment magnitudes of the earthquakes were determined from the fault lengths of the three rupture planes, using the surface rupture length-magnitude formula in Wells and Coppersmith (1994) as a guide.

The rise times of slip for each sub-fault were determined by specifying an average slip velocity following the procedure of Frankel (2009), which compared the spectral acceleration from synthetics with those predicted by the Next Generation of Attenuation (NGA) relations. Frankel (2009) determined that an average slip velocity of $2.7 \mathrm{~m} / \mathrm{s}$ reproduced the 1.0 and $3.0 \mathrm{~s}$ spectral accelerations of the NGA relations for earthquakes with M5.5, 6.5, and 7.5. The dynamic stress drop is proportional to the slip velocity divided by the rupture velocity ( $\mathrm{Vr}$ ). Because the Vr is specified as a fraction of the local shear-wave velocity, the average slip velocity was multiplied by the sub-fault Vs divided by3,500 m/s, to approximately maintain a constant dynamic stress drop as the Vs varies with the location of the sub-fault. The slip velocity was randomized with a uniform distribution with \pm 20 percent variation. The rise time for each sub-fault was determined from the ratio of the final slip divided by the slip velocity. A Brune (1970) pulse was used for the source time function for each sub-fault.

One key set of parameters is the rupture initiation time for each sub-fault. The fraction of $\mathrm{Vr} / \mathrm{Vs}$ for each sub-fault was varied between 0.62 and 0.98 . The variation in Vr was specified as 20 percent standard deviation around 0.8 of the local Vs. The perturbation in the rupture velocity was proportional to the final slip for that sub-fault, such that areas with higher slip have faster rupture velocity. This follows results of dynamic rupture simulations. The Vs varied with position along each rupture plane according to the location of the rupture in the 3D model. Twodimensional ray tracing along the rupture plane was used to calculate the initiation time of each sub-fault. Separate ray-tracing runs were done to calculate the initiation time of each sub-fault. The local rupture velocity for each ray-tracing run was calculated from the $\mathrm{Vr} / \mathrm{Vs}$ fraction determined for that given sub-fault. In this manner, areas with high slip will rupture sooner than adjacent areas with low slip. We also added a small random component to the rupture time of each sub-fault, similar to that done in Frankel (2009). The rupture initiation times for one of the simulations of the Rattlesnake Hills West rupture is shown in figure 24. There is quite a bit of randomness to the initiation times, similar to that reported in dynamic rupture simulations with complex pre-stress and strength. The rake of each sub-fault is derived from a uniform random distribution with a variation of \pm 20 degrees around the average rake of 120 degrees.

\section{One-Dimensional Models and Reflectivity Method}

Ten rupture scenarios were done for each fault source, resulting in 30 3D simulations. For each scenario, random draws were taken for the along-strike and down-dip locations of the hypocenter and for choosing among five slip distributions generated with different random number seeds. The down-dip location of the hypocenter was constrained to be within the lower one-half of the rupture. This has been the case for all M6.5 or larger oblique or thrust earthquakes in California since 1970 that have well-resolved hypocentral and aftershock depths.

The 3D and 1D simulations used the same source files, specifying the seismic moment, start time, rise time, and focal mechanism for each sub-fault. 
Green's function for the 1D model for each station were calculated using the frequencywavenumber integration code of Zhu and Rivera (2002). The 1D model for each of the five stations was developed by Paul Thorne. We decided to follow an approach suggested by the Technical Integration Team for the SSHAC study. Beneath the Grand Ronde basalts, we used the same velocity profile for all five stations. The $1 \mathrm{D}$ velocity model for depths greater than $3 \mathrm{~km}$ corresponded to the Vs profile at the center (measured along strike) of the rupture plane for each fault, as determined from the 3D model. This ensures that the Vp, Vs, and density values with depth for the sub-faults are approximately the same between the 3D and 1D models. For the Rattlesnake Hills West and Gable Mountain ruptures, it was found that the Vs profiles between 3 and $15 \mathrm{~km}$ were equivalent in the 3D model. Therefore, the same 1D velocity models were used for these faults at depths greater than $3 \mathrm{~km}$. The Vs profiles for the five sites used in the 1D simulations for the Rattlesnake Hills West and Gable Mountain sources are shown in figure 25. Separate sets of Green's functions were calculated for the five sites for the Rattlesnake Hills East and Cascadia sources. The depth to basement for the Rattlesnake Hills East source was about 820 $\mathrm{m}$ less than that for the Rattlesnake Hills West and Gable Mountain sources. The depth to basement for the Cascadia source was 340 m greater than the Rattlesnake Hills West and Gable Mountain sources. There also were some differences in the depth to top of pre-Miocene sediments between these profiles that were incorporated in the velocity profiles. All together, there were 15 sets of 1D Green's functions calculated (5 sites and 3 different profiles for depths greater than $3 \mathrm{~km}$ ). There were150 1D simulations completed: 3 rupture zones, 10 scenarios for each rupture zone, and 5 Vs profiles for each scenario.

Because of the large number of $1 \mathrm{D}$ simulations requested by the Technical Integration Team, the 1D simulations could not be completed using the 3D finite-difference code in the allotted time. We compared the waveforms and spectral accelerations between the synthetics from the reflectivity summation code and the 3D code using the same $1 \mathrm{D}$ velocity profile and source file. We determined that the spectral accelerations were within 20 percent at 0.5 and 0.75 $\mathrm{s}$ and within 10 percent for periods greater than or equal to $1.0 \mathrm{~s}$. The velocity waveforms at any given station were almost identical. The ratios of spectral accelerations shown below are for the pseudo spectral accelerations, using the geometrical average of the two horizontal components.

\section{Rattlesnake Hills Fault, West, Moment Magnitude 6.8}

Synthetics from the 3D model at sites A (200 East area) and B (200 West area) for the Rattlesnake Hills West source show substantial later arrivals after the initial S-wave, arrivals that are not present in the synthetics from the 1D models with the same source (fig. 26). The 1D synthetics shown for each site were simulated with the 1D model for that site. Sites A and B have the largest thickness of supra-basalt sediments, 94 and $39 \mathrm{~m}$, respectively (fig. 1). At site A, the peak velocity in the 3D synthetics occurs 10-20 s after the initial S-wave, in contrast to the short-duration 1D synthetics (fig. 26). These later arrivals in the 3D synthetics likely are surface waves produced by conversion of incident S-waves at the southern edge of the supra-basalt sediments. These surface waves also may be reflected and amplified by other features in the shallow portion of the 3D velocity model. For the other sites (C, D, and E), the 3D and $1 \mathrm{D}$ synthetics are similar, although there is short-period energy superimposed on the long-period waveforms in the 3D synthetics that is not present in the $1 \mathrm{D}$ synthetics (fig. 26). This indicates 
that the reverberations of S-waves in the supra-basalt sediments may be stronger in the 3D model than the 1D model. This could be caused by the non-horizontal interface in the 3D model at the base of the supra-basalt sediments. The thickness of supra-basalt sediments in the 1D models for sites C, D, and E are 14, 25, and $17 \mathrm{~m}$, respectively.

Most sites show higher spectral accelerations at periods of $0.5,0.75$, and $1.0 \mathrm{~s}$ for the 3D model than the 1D models. The natural logarithm (ln) of the ratios of the spectral accelerations between the $3 \mathrm{D}$ and $1 \mathrm{D}$ synthetics are shown in figure 27 . This figure displays the 3D/1D ratios at each site for the 10 simulations for that rupture zone, as well as the mean and standard deviation of the $\ln$ ratio at each period. The spectral accelerations for periods of 3-10 s generally are similar between the 3D and 1D synthetics for all the sites. There is substantial variation in the ratios at each site between the 10 source scenarios, although the general dependence on period is similar. The standard deviations of the ratios generally decrease with increasing period. At periods of less than or equal to $2 \mathrm{~s}$, the standard deviations of the ln ratios for the 10 simulations can be as large as about 0.3 ln units.

The ratios between the $3 \mathrm{D}$ and $1 \mathrm{D}$ models are largest for sites $\mathrm{A}$ and $\mathrm{B}$ with the thickest supra-basalt sediments. For site A, the ratios start to increase at $2 \mathrm{~s}$ period, reach a peak oln ratio of 1.5 (factor of 4.5 ) at $0.75 \mathrm{~s}$, and have a ln ratio of 1.1 (factor of 3.0) at $0.5 \mathrm{~s}$. At site $\mathrm{B}$, the ratios start to increase at $1.5 \mathrm{~s}$, reaching $\ln$ ratio of 1.1 (factor of 3.0) at $0.5 \mathrm{~s}$. The 3D/1D ratios at site $\mathrm{C}$ start to increase at $1 \mathrm{~s}$ and have a maximum ln ratio of 0.75 (factor of 2.1) at $0.5 \mathrm{~s}$. The ratios at site $\mathrm{D}$ start to increase at $2 \mathrm{~s}$ and peak at $0.75 \mathrm{~s}$ at a ln ratio of 1.0 . For site $\mathrm{D}$, the $\ln$ of the ratios are slightly negative for 3-5 s, indicating that the spectral accelerations for the 3D synthetics are slightly smaller than those for the 1D synthetics at those periods. The ln of the 3D/1D ratios at site E are smaller, with no values greater than 0.5 (less than a factor of 1.6).

The ratios generally increase with decreasing period, starting at some transition period. This transition period is greater for sites A and B with the thickest supra-basalt sediments than those for the other sites.

We were initially concerned that the $3 \mathrm{D} / 1 \mathrm{D}$ ratios for site $\mathrm{C}$ could be affected by the discretization of the 3D model. For site C, the thickness of the supra-basalt sediments is $14 \mathrm{~m}$, less than the vertical grid spacing ( $25 \mathrm{~m}$ ) used in the 3D model. The thickness of the sediments in the 3D model is set to one grid spacing for this site (fig. 1). For vertically propagating S-waves, the resonance frequency is about $5 \mathrm{~Hz}$ for a $25 \mathrm{~m}$ thick layer with Vs of $425 \mathrm{~m} / \mathrm{s}$. So the resonance frequency is lower in the 3D model than in the $1 \mathrm{D}$ models, where the supra-basalt layers are not discretized. We were concerned that this may cause the 3D synthetics to have higher spectral accelerations at 0.5 and $0.75 \mathrm{~s}$ than the $1 \mathrm{D}$ synthetics. However, we tested this idea by making 1D synthetics at site C using Green's functions calculated for site D, which has a thickness of $25 \mathrm{~m}$. We found no significant difference in the spectral accelerations at $0.5,0.75$, and $1.0 \mathrm{~s}$ at site $\mathrm{C}$ between the 1D models with thicknesses of 25 and $14 \mathrm{~m}$, indicating that the differences between the 3D and 1D values are not driven by the variation in sediment thickness between the 3D and $1 \mathrm{D}$ models. The observation that the 3D/1D ratios for site $\mathrm{E}$, which has a sediment thickness of $17 \mathrm{~m}$, are close to 1 also indicates that the discretization of the 3D model is not the cause of the higher ratios at site $\mathrm{C}$. 


\section{Rattlesnake Hills Fault, East, Moment Magnitude 6.7}

The synthetics from the 3D model for the Rattlesnake Hills East source also display prominent later arrivals after the S-waves at sites A and B, indicating basin surface waves that are not present in the $1 \mathrm{D}$ synthetics (fig. 28). The peak arrivals in the $3 \mathrm{D}$ synthetics for these sites occur well after the initial S-wave, indicating that these late arrivals are basin surface waves not present in the $1 \mathrm{D}$ models. The $3 \mathrm{D}$ and $1 \mathrm{D}$ synthetics at sites $\mathrm{C}, \mathrm{D}$, and $\mathrm{E}$ are similar, although there is more high-frequency energy apparent in the 3D synthetics. The synthetics at site $\mathrm{E}$ contain a strong S-wave pulse from rupture directivity.

The ratios of the 3D/1D spectral accelerations show that the 3D model produces higher spectral accelerations at 0.5-1.0 s at all the sites, with the largest ratios at sites A and B (fig. 29). For site A, the ratios start to increase at $2 \mathrm{~s}$ and peak at $0.75 \mathrm{~s}$ at a ln ratio of 1.3 (factor of 3.7). The $\ln$ ratios at site $\mathrm{B}$ are slightly negative at 3 and $4 \mathrm{~s}$. The $3 \mathrm{D} / 1 \mathrm{D}$ ratios start to increase at $2 \mathrm{~s}$ and reach a $\ln$ ratio of 1.0 at 0.75 and $0.5 \mathrm{~s}$. The ratios at site $C$ are positive for 0.5 and $0.75 \mathrm{~s}$, and have a peak $1 \mathrm{n}$ ratio of about 0.75 (factor of 0.75 ). The $3 \mathrm{D} / 1 \mathrm{D}$ ratios are small at site $\mathrm{D}$, reaching $\ln$ ratio of 0.5 at 0.5 and $0.75 \mathrm{~s}$. For site E, the ln ratio increases to about 0.9 (factor of 2.5) at $0.5 \mathrm{~s}$.

\section{Gable Mountain Fault, Moment Magnitude 6.6}

This source is different from the Rattlesnake Hills sources in that most of the PSHA sites are directly or nearly above the rupture. S-waves traveling from the source to these sites are upward propagating and do not interact with the edge of the area with supra-basalt sediments, except perhaps by reflection. However, the 3D structure could potentially cause focusing of the upward-traveling S-waves.

1D and 3D synthetics for one of the Gable Mountain sources are shown in figure 30. For sites A,B,C, and D, the 3D and 1D synthetics for each site look similar and contain strong Swave pulses produced by forward rupture directivity. There appears to be more high-frequency energy in the $3 \mathrm{D}$ synthetics than in the 1Dsynthetics. The 3D synthetics at site $\mathrm{E}$, the farthest from the source, have prominent later arrivals that are not present in the $1 \mathrm{D}$ synthetics. This is especially notable on the vertical component. The 3D model is apparently producing more basin surface waves at this relatively distant site than the 1D model.

For most of the sites, the 3D/1D ratios of spectral accelerations (fig. 31) are smaller than those determined for the Rattlesnake Hills sources, but still can be significant in some cases. The 3D/1D ratio for the spectral accelerations was largest for site E, with values reaching a ln ratio of 1.0 (factor of 2.8) at $0.5 \mathrm{~s}$. The $3 \mathrm{D} / 1 \mathrm{D}$ amplifications were small for site A and actually negative at $0.5 \mathrm{~s}$. The ratios at sites $\mathrm{B}, \mathrm{C}$, and $\mathrm{D}$ reach a ln ratio of 0.6 (factor of 1.8 ) at $0.5 \mathrm{~s}$.

\section{Cascadia}

To approximate an incoming S-wave from an earthquake on the Cascadia subduction zone, we used a set of sources arranged as a dipping plane beneath the western portion of the 3D velocity model. The planar source consisted of sources at $500 \mathrm{~m}$ spacing with a north-south strike and a dip of 41 degrees, down to the east. This dip was selected because it represents the angle of incidence of a critical reflection from the Moho, for a Vs of 3,500 m/s in the crust and 
$4,600 \mathrm{~m} / \mathrm{s}$ in the top of the mantle. The sources at all of these grid points are initiated at the same time. A focal mechanism with a strike of 0 degrees, dip of 41 degrees, and rake of 90 degrees was applied to each source. A rise time of $6 \mathrm{~s}$ was used for each source point, approximating that expected for a great Cascadia earthquake. This rise time is not important to the spectral acceleration ratios. The same source file was used for the 3D and 1D simulations.

The 3D and 1D synthetics generally display a simple S-wave pulse (fig. 32) with shortperiod energy superimposed. The 3D synthetics have stronger, short-period reverberations after the initial arrival than the 1D synthetics. Site E, farthest to the east, shows a long-period arrival about $10 \mathrm{~s}$ after the initial S-wave on the vertical and east-west (radial) components of the 3D and $1 \mathrm{D}$ synthetics.

There is substantial amplification of the spectral accelerations from the 3D model with respect to those from the $1 \mathrm{D}$ model. The ratios of the spectral accelerations for the $3 \mathrm{D}$ and $1 \mathrm{D}$ simulations for the five PSHA sites are shown in figure 33. Again, the 1D simulations used Green's functions calculated for the 1D model for each site. Amplification of the synthetics from the $3 \mathrm{D}$ simulation relative to the $1 \mathrm{D}$ simulations increased from periods of $1.0-0.5 \mathrm{~s}$. The ratio for site A peaks at $0.75 \mathrm{~s}$ with ln ratio of 2.2 (factor of 9) and was $\ln$ ratio of 1.5 at $0.5 \mathrm{~s}$ and $\ln$ ratio of 1.3 at $1.0 \mathrm{~s}$. For site $\mathrm{C}$, the $3 \mathrm{D} / 1 \mathrm{D}$ ratio was $\ln$ ratio of 0.5 (factor of 1.6 ) at $4 \mathrm{~s}$ and increased to $\ln$ ratio of 1.4 (factor of 4.1 ) at 0.75 and 0.5 s. For site $D$, the $3 \mathrm{D} / 1 \mathrm{D}$ ln ratio was1.4 (factor of 4.1 ) at $0.5 \mathrm{~s}$. Site E shows the lowest amplification, reaching ln ratio of 0.5 (factor of $1.6)$ at 0.75 and $0.5 \mathrm{~s}$.

It should be emphasized that the dipping-plane wave source for Cascadia is a pragmatic simplification. Obviously, the input regional S-wave will have a more complicated configuration because of the structure between the subduction zone and the western portion of the 3D model used here. This configuration also cannot assess the amplification of regional surface waves from the Cascadia source.

\section{Conclusions}

The three-dimensional (3D) model produces synthetics that are a better fit to the observed waveforms, durations, spectral accelerations, and energy for the Prosser earthquake than the synthetics from the one-dimensional (1D) model. The 3D model reproduces the observed basin surface waves from the Prosser earthquake, surface waves that were likely created along the southern edge of the supra-basalt sediments and whose large amplitudes cannot be explained with the 1D model. The synthetics from the 3D model for the Wooded Island and Walla Walla, Washington, earthquakes show durations of shaking more similar to the observed records, whereas the $1 \mathrm{D}$ synthetics do not display the later arrivals seen in the data.

For the simulations of magnitude 6 earthquakes on the Rattlesnake Hills fault, the 3D model produced synthetics with substantially higher spectral accelerations at periods from 0.5 to 1.0 seconds (s) than the $1 \mathrm{D}$ models. The durations of the $3 \mathrm{D}$ synthetics at sites $\mathrm{A}$ and $\mathrm{B}$ are much longer than those from the 1D models. The ratios between the $3 \mathrm{D}$ and $1 \mathrm{D}$ spectral accelerations reach a factor 4.5 and generally are larger for the sites with the thickest supra-basalt sediments (sites A and B). The 3D/1D ratios typically are more subdued for the Gable Mountain source, although they still can be significant. For the Cascadia plane-wave source, the amplification of 0.2 and $1.0 \mathrm{~s}$ spectral accelerations of the 3D model relative to the $1 \mathrm{D}$ models is substantial (as much as a factor of 9 for one site) at most of the sites and significant amplification extended to periods as long as $4 \mathrm{~s}$ period for one site. 
This study has demonstrated that simulations in a 3D velocity model for the Hanford area are required to accurately predict the spectral acceleration, energy, and duration of strong ground motions from moderate and large earthquakes on the Rattlesnake Hills and Gable Mountain faults, as well as from great earthquakes on the Cascadia subduction zone. These 3D effects need to be considered to properly assess the probabilistic seismic hazard for structures and storage tanks at the Hanford facility and the Columbia Nuclear Generating Station. The deployment of dense arrays of surface seismometers and borehole arrays on the Hanford facility would help to better quantify and predict strong ground motions from future earthquakes.

\section{Acknowledgments}

The U.S. Department of Energy provided funding for this study, as part of the Senior Seismic Hazard Analysis Committee probabilistic seismic hazard assessment for the Hanford facility. We thank Robert Bryce for his support of this project, for his assistance with coordinating this effort, and for his comments on the report. Stephen Reidel helped produce the $3 \mathrm{D}$ velocity model and his insights on the constraints for the model were illuminating. We thank Pengcheng Liu for providing his 3D finite-difference program. Larry Baker helped with optimizing the program. We thank Julian Bommer, Robert Youngs, Gabriel Toro, Ken Campbell, Adrian Rodriguez-Marek, Linda Al Atik, and Walter Silva for their comments and suggestions. Earthquake seismograms, locations, focal mechanisms, and magnitudes provided by the Pacific Northwest Seismic Network were essential to this study. We thank Craig Weaver for his support and advice. Paul Bodin and John Vidale reviewed the report and provided helpful comments.

\section{References Cited}

Alford, R.M., Kelley, K.R., and Boore, D.M., 1974, Accuracy of finite-difference modeling of the acoustic wave equation: Geophysics, v. 39, p. 834-842.

Brune, J.N., 1970, Tectonic stress and the spectra of seismic shear waves from earthquakes: Journal of Geophysical Research, v. 76, p. 4,997-5,002.

Burns, E.R., Morgan, D.S., Peavler, R.S., and Kahle, S.C., 2011, Three-dimensional model of the geologic framework for the Columbia Plateau Regional Aquifer System, Idaho, Oregon, and Washington: U.S. Geological Survey Scientific Investigations Report 2010-5246, 44 p., http://pubs.usgs.gov/sir/2010/5246/.

Frankel, A.D., 2009, A constant stress-drop model for producing broadband synthetic seismograms - comparison with the Next Generation Attenuation relations: Bulletin of the Seismological Society of America, v. 99, p. 664-680.

Frankel, A.D., Stephenson, W.J., Carver, D.L., Williams, R.A., Odum, J.K., and Rhea, S., 2007, Seismic hazard maps for Seattle incorporating 3D sedimentary basin effects, nonlinear site response, and rupture directivity: U.S. Geological Survey Open-File Report, 2007-1175, 70 p. 
Frankel, A., Stephenson, W., and Carver, D., 2009, Sedimentary basin effects in Seattle, Washington: ground-motion observations and 3D simulation: Bulletin of the Seismological Society of America, v. 99, p. 1579-1611.

Geomatrix, 1996, Probabilistic seismic hazard analysis-DOE Hanford site, Washington: San Francisco, California, Geomatrix Consultants, Inc., WHC-SD-W236A-TI-002, rev. 1, Glover, D.W., 1985, Crustal structure of the Columbia Basin, Washington, from borehole and refraction data: University of Washington, Geophysics Program, MS Thesis.

Liu, P-C, and Archuleta, R.J., 2002, The effect of a low-velocity surface layer on simulated ground motion: Seismological Research Letters, v. 73, p. 267.

Mai, P.M., and Beroza, G.C., 2002, A spatial random field model to characterize complexity in earthquake slip: Journal of Geophysical Research, v. 107, p. 1-21.

Wells, D.L., and Coppersmith, K.J., 1994, New empirical relationships among magnitude, rupture length, rupture width, and surface displacements: Bulletin of the Seismological Society of America, v. 84, p. 974-1,002.

Zhu, L., and Rivera, L., 2002, Computation of dynamic and static displacement from a point source in multi-layered media: Geophysical Journal International, v. 148, p. 619-627. 


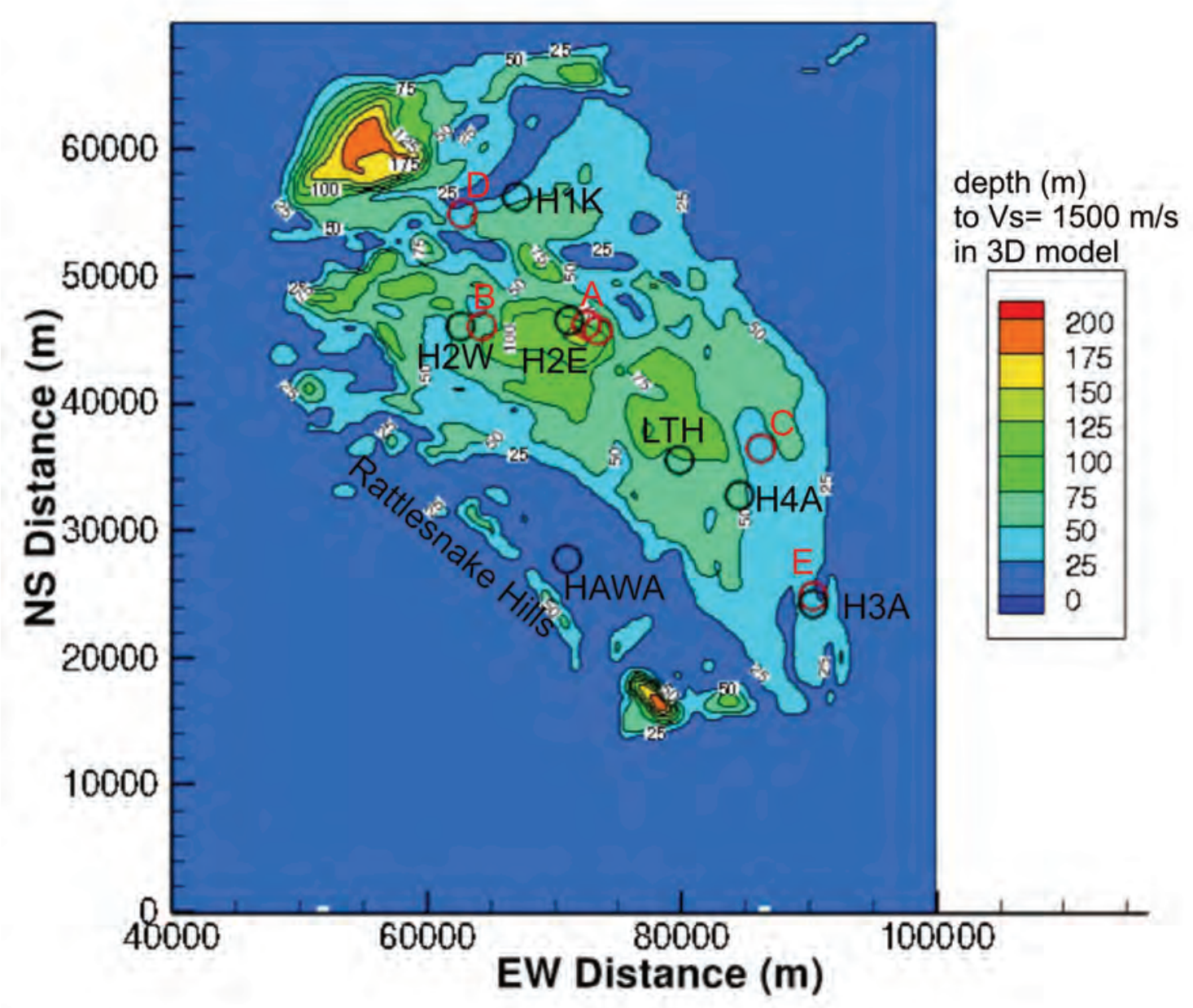

Figure 1. Map of depth (meters) to S-wave velocity (Vs) of 1,500 meters per second for the Hanford area, Washington. This equals the thickness of the supra-basalt sediments in the three-dimensional (3D) model. Contour interval is 25 meters, the same as the vertical grid spacing in the 3D model. Black circles are seismic stations (labeled). Red circles are locations of sites used in the probabilistic seismic hazard assessment. 


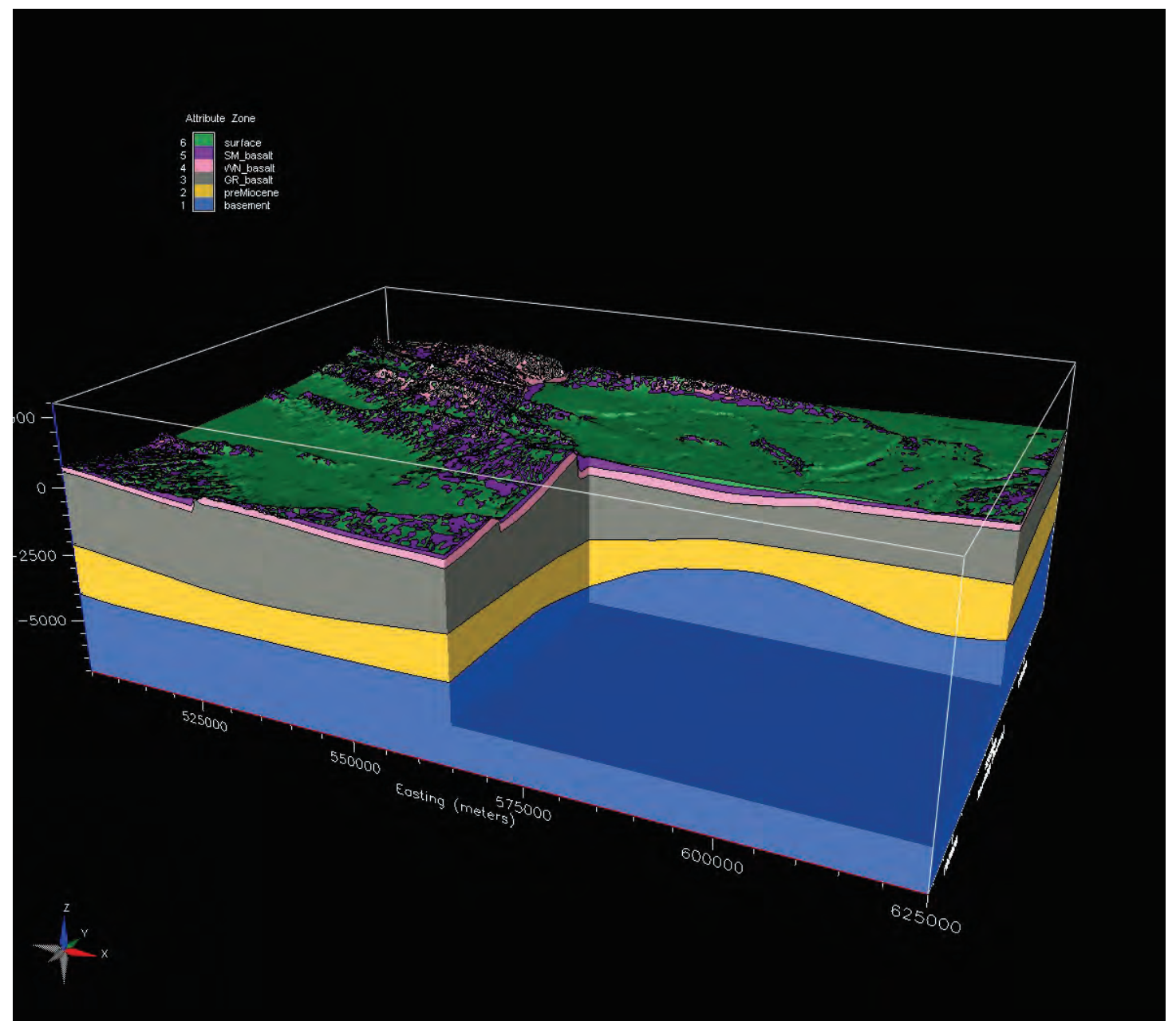

Figure 2. Cut-out view of three-dimensional (3D) velocity model that used depth to basement derived from gravity-derived model (GDM). Blue is basement, yellow designates sub-basalt sediments, gray represents basalts, and pink and purple denote supra-basalt sediments. 

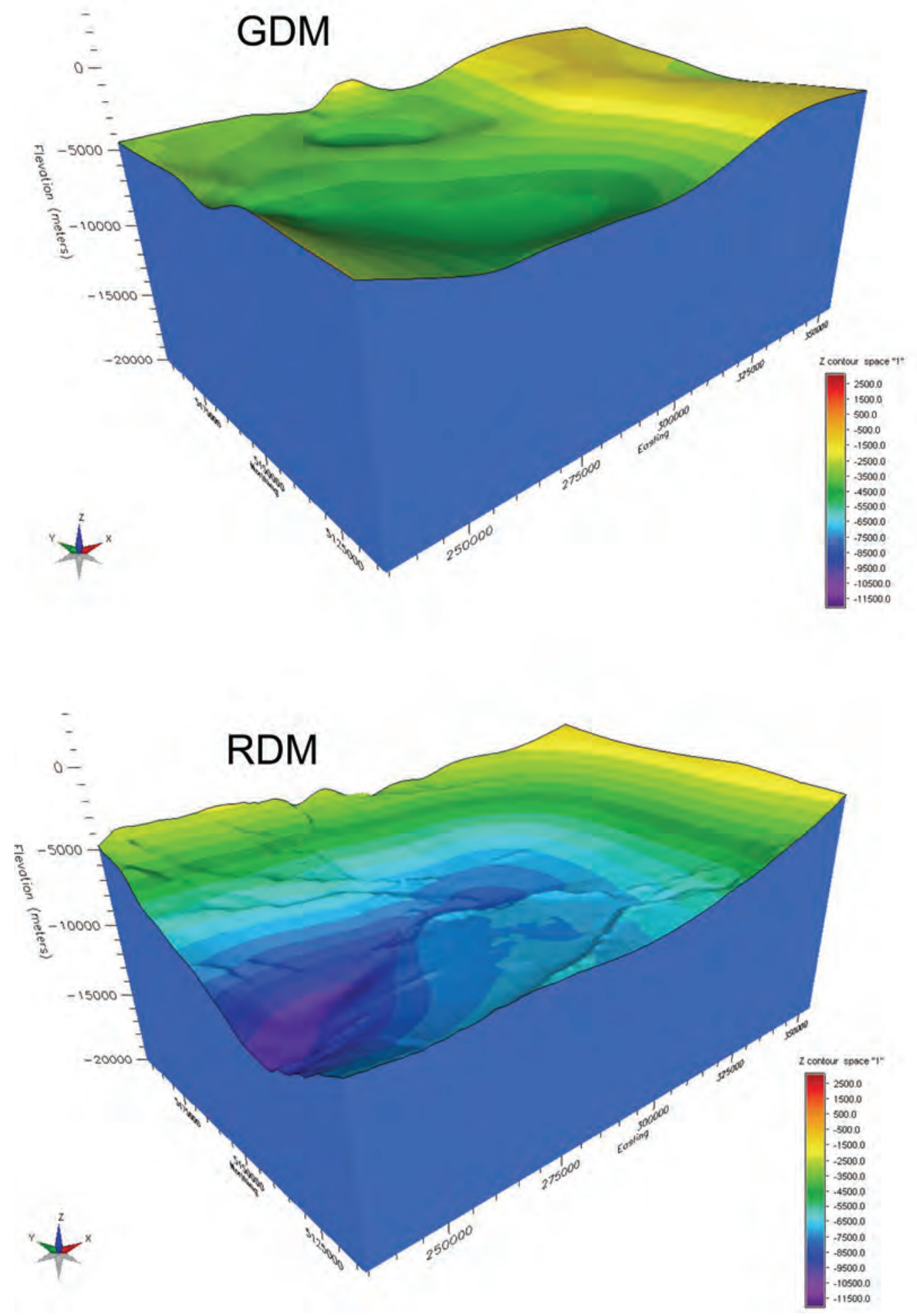

Figure 3. 3D views of the elevation of the top of basement $(\mathrm{m})$ for the gravity-derived model (GDM; top) and the refraction-derived model (RDM; bottom). 


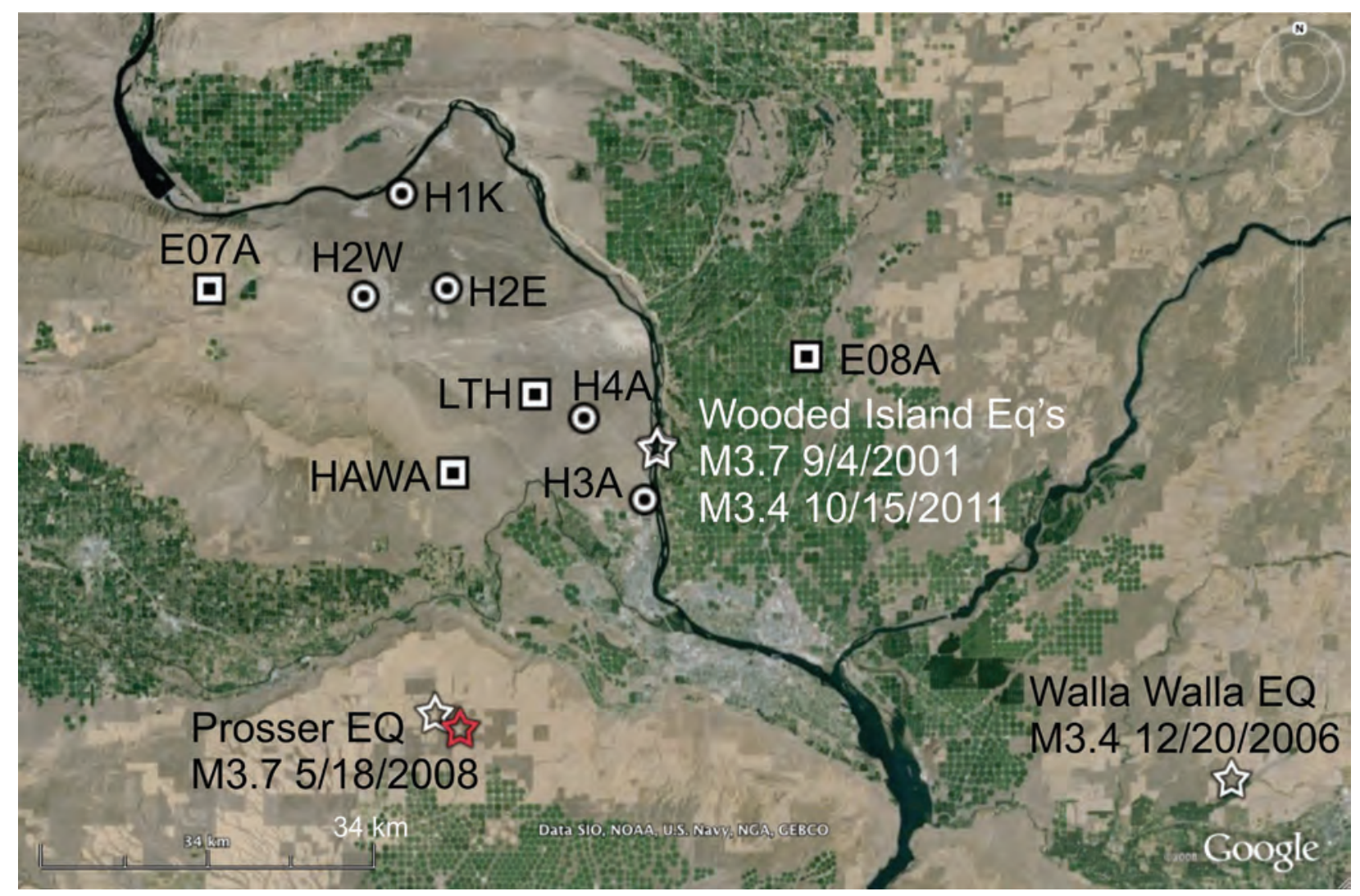

Figure 4. Satellite image of Hanford area from GoogleEarth ${ }^{\mathrm{TM}}$ showing locations of strong-motion accelerometers (circles), broadband stations (squares), and earthquakes studied (stars). Red star indicates initial location of Prosser earthquake from Pacific Northwest Seismic Network (PNSN); white star represents re-location from database of A. Rodriguez-Marek. Other earthquake epicenters from PNSN. The two Wooded Island earthquakes have very similar epicenters. 

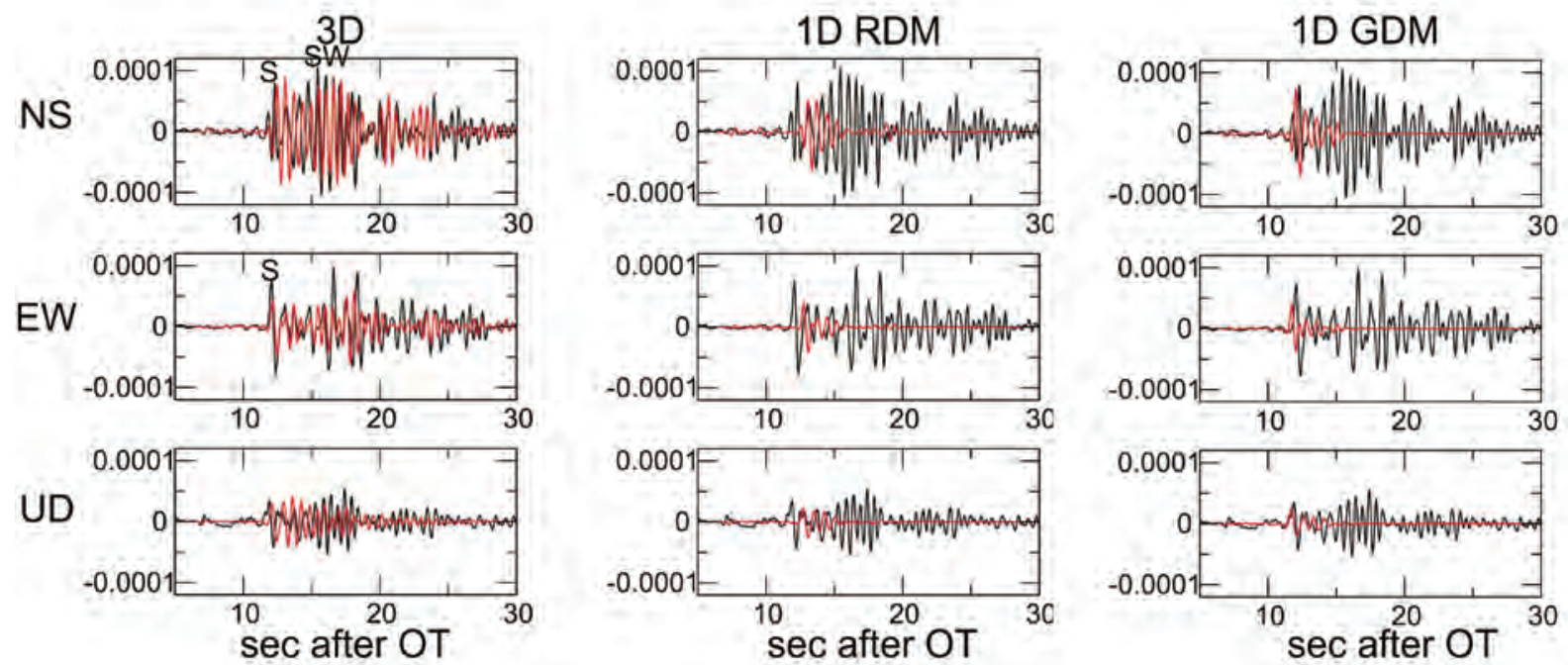

Figure 5. Observed (black) and synthetic (red) velocity waveforms at station $\mathrm{H} 4 \mathrm{~A}$ for the Prosser earthquake. Vertical scale is in meters per second. Left panel shows synthetics from 3D velocity model. Center and right panels show synthetics using 1D models in figure 5 . The synthetics from the 3D model show substantial arrivals after the S-wave similar to the observed waveforms. These later arrivals are surface waves (labeled SW) created by the 3D structure. The synthetics from the 1D models do not reproduce the observed arrivals after the S-wave. GDM, gravity-derived model; RDM, refraction-derived model; NS, north-south; EW, east-west; UD, up-down; OT, origin time. 


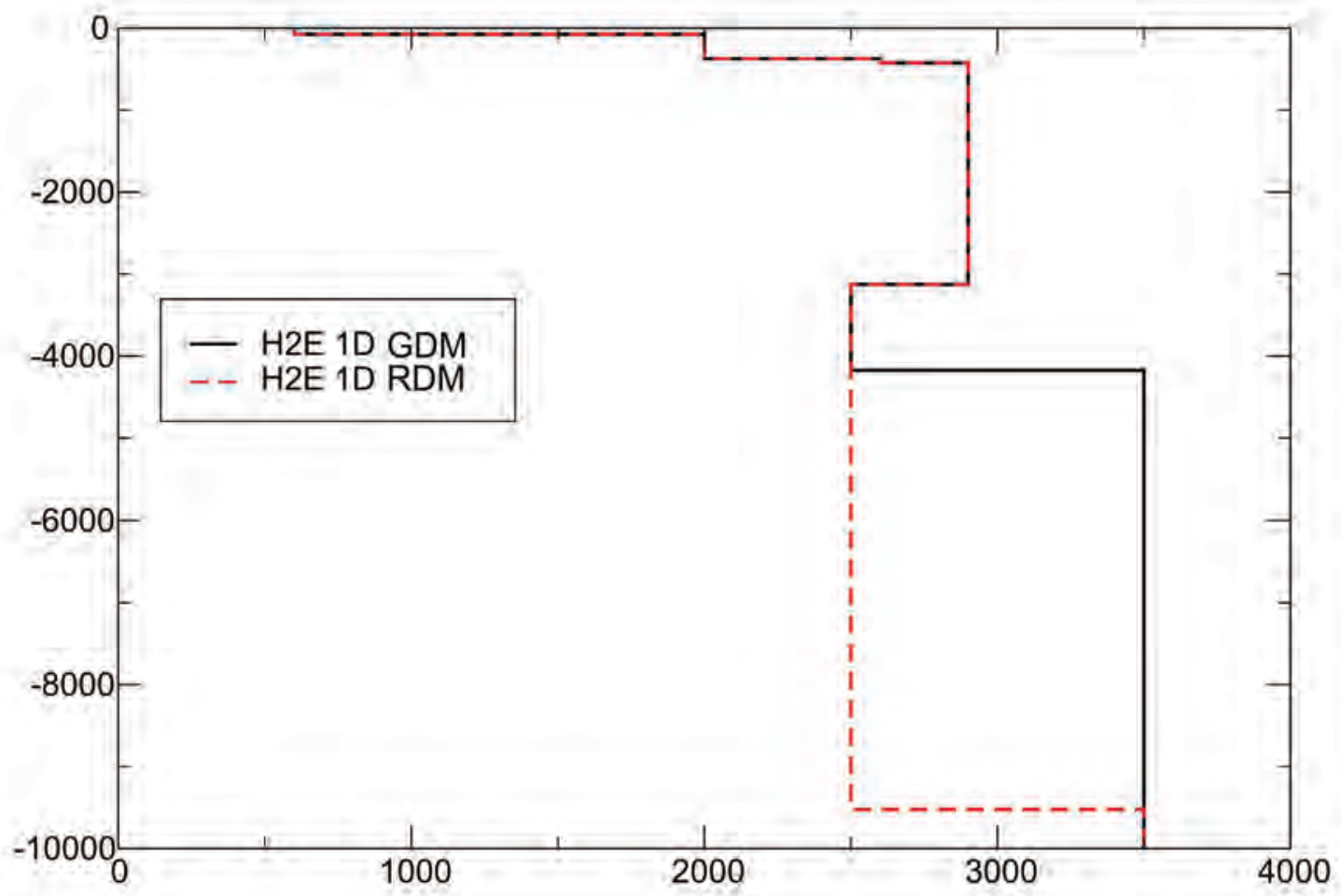

Figure 6. One-dimensional (1D) velocity profiles at station H2E used in the modeling of the recorded earthquakes. The gravity-derived model (GDM) uses the depth to top of basement derived from gravity modeling. The refraction-derived model (RDM) applies the depth to top of basement constrained by seismic refraction studies. 

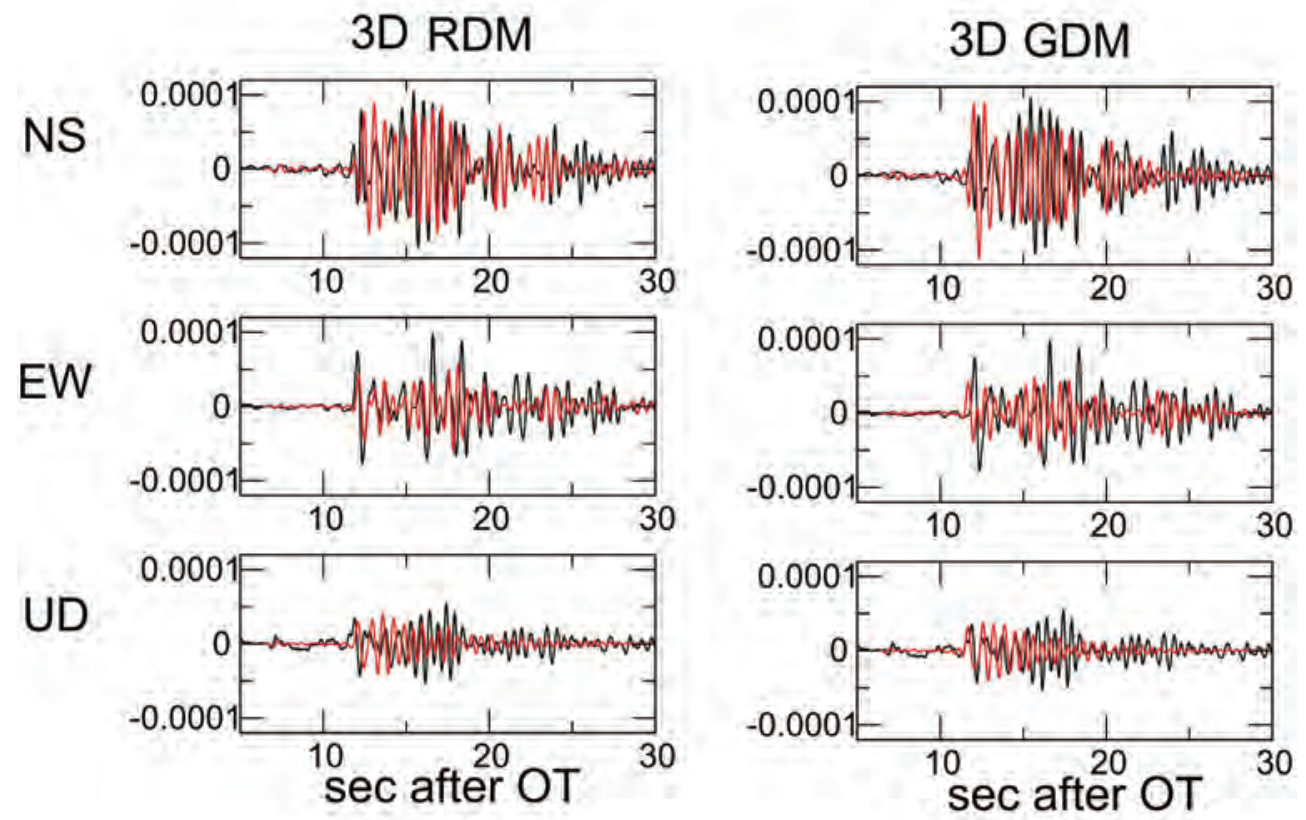

Figure 7. Observed (black) and synthetic (red) velocity waveforms at station H4A for the Prosser earthquake. The synthetics were made with two three-dimensional (3D) crustal models (refraction-derived model [RDM] and gravity-derived model [GDM]), with different depths to top of basement. 

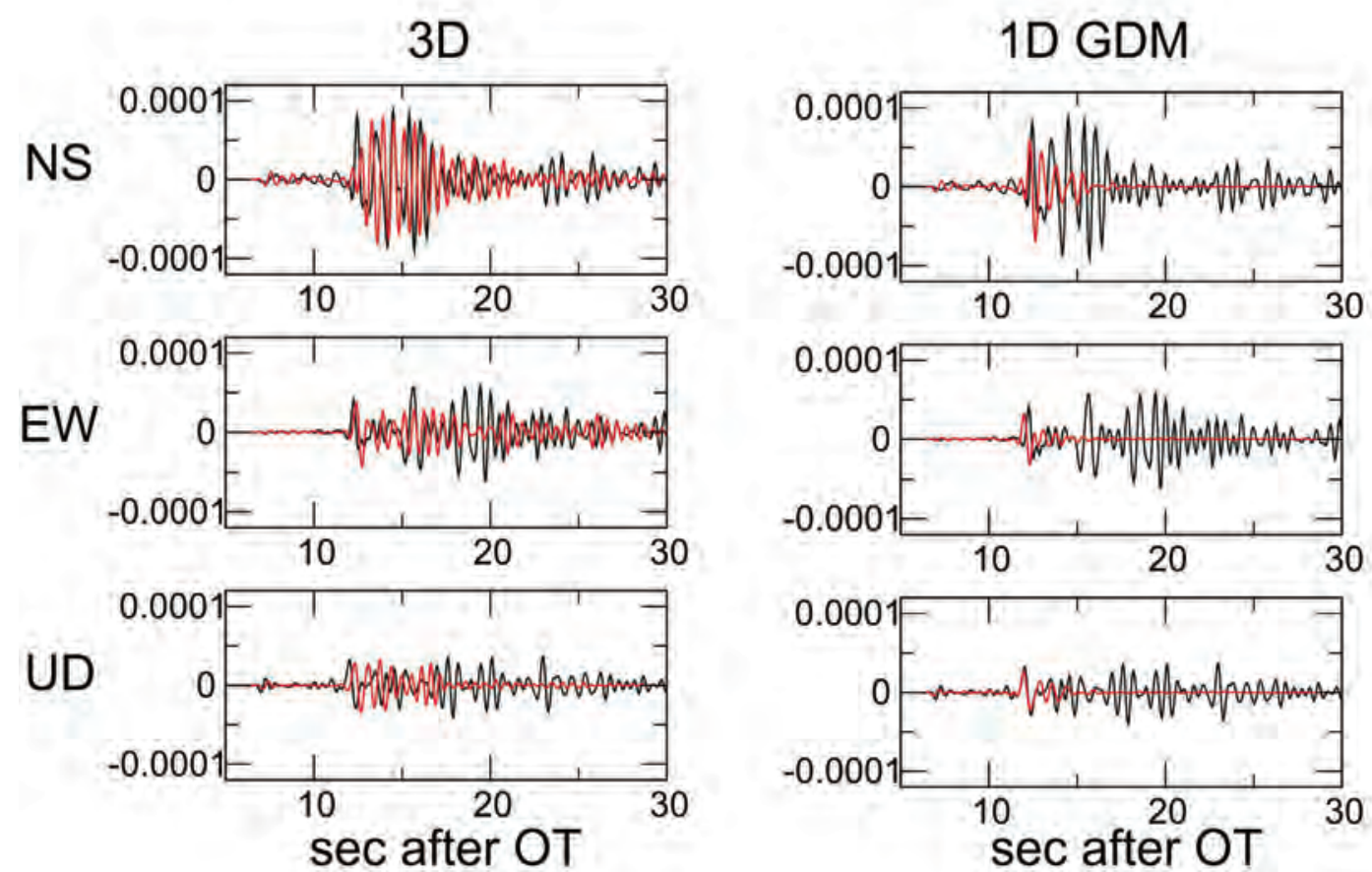

Figure 8. Observed (black) and synthetic (red) velocity waveforms at station LTH for the Prosser earthquake. Note that the synthetics from the three-dimensional (3D) model capture much of the energy observed after the S-wave, whereas the one-dimensional gravity-derived model (1D GDM) synthetics do not. 

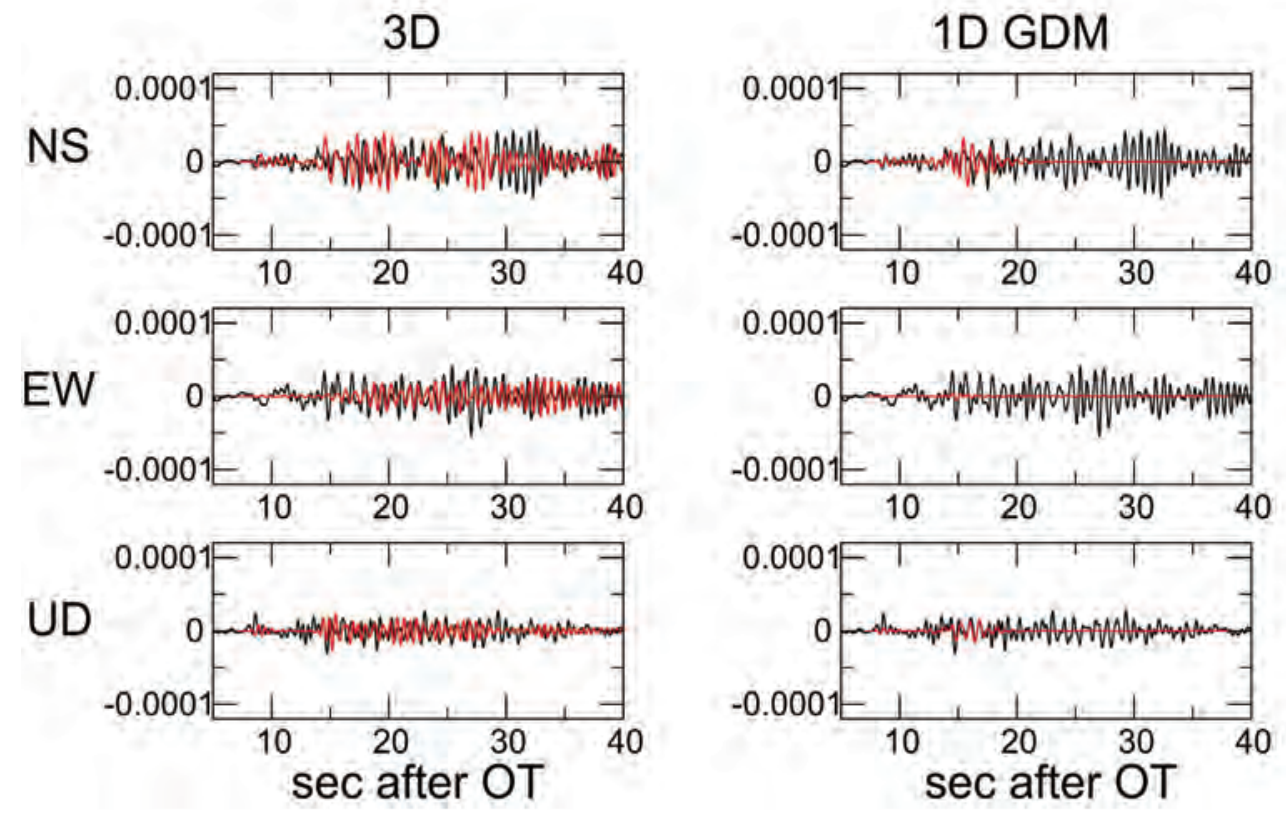

Figure 9. Observed (black) and synthetic (red) velocity waveforms at station H2E for the Prosser earthquake. Left panel shows synthetics for the 3D model. Right panel shows synthetics for the 1D model. 

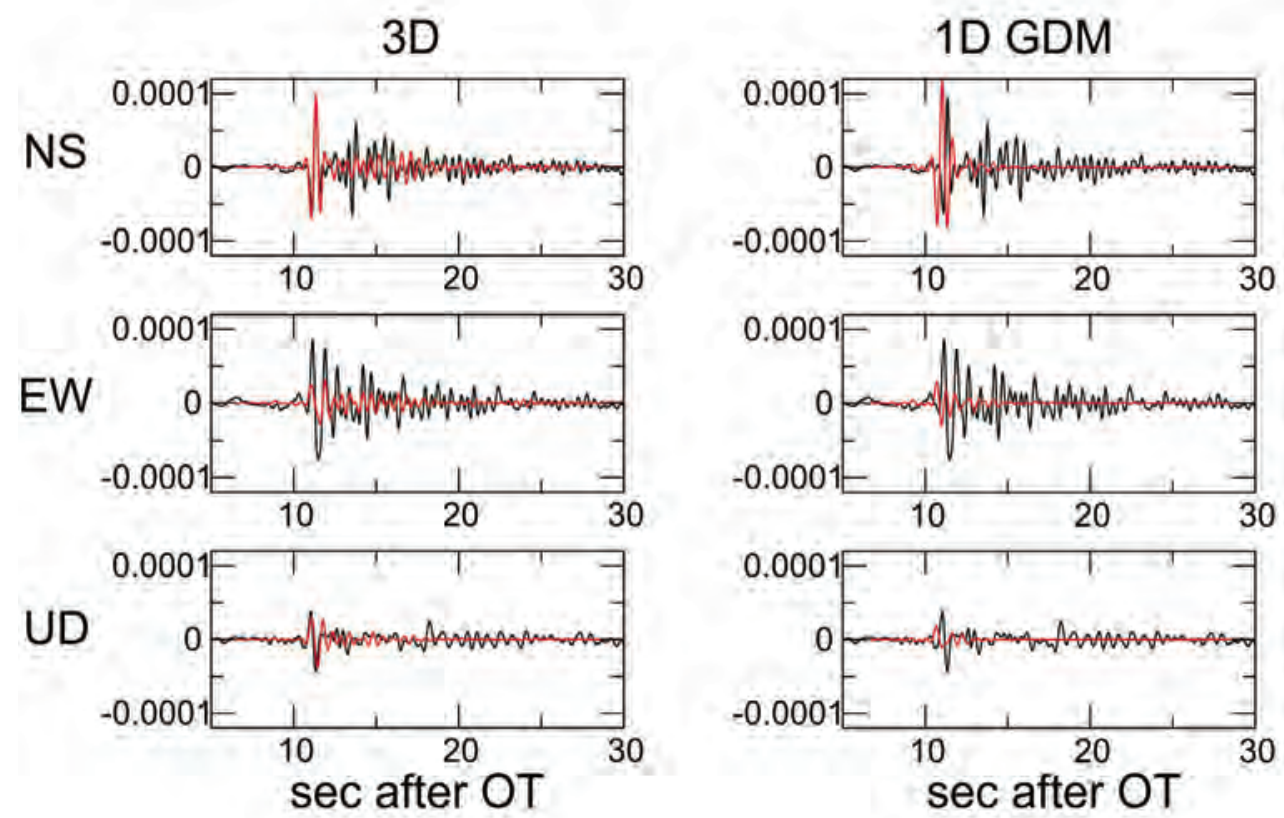

Figure 10. Observed (black) and synthetic (red) velocity waveforms at station H3A for the Prosser earthquake. Left panel shows synthetics for the 3D model. Right panel shows synthetics for the 1D model. 
$3 \mathrm{D}$
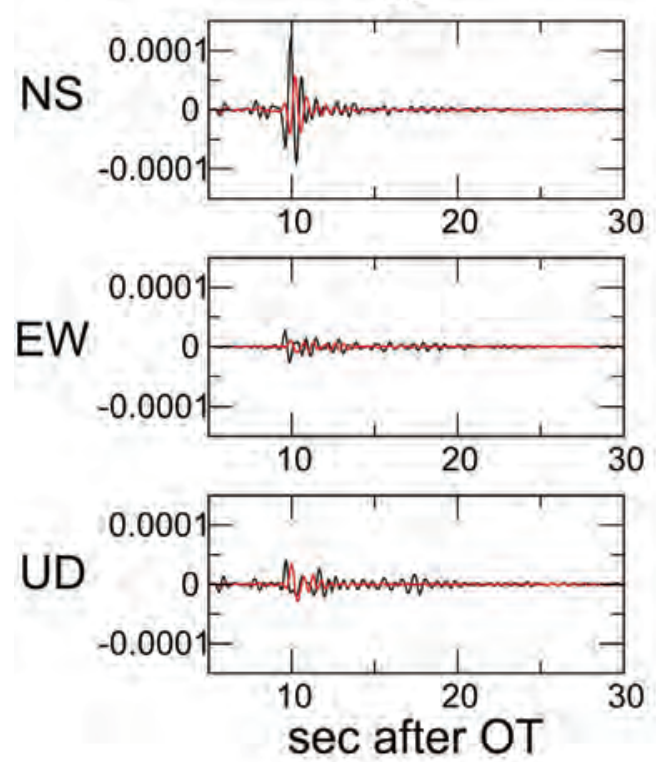

1D GDM
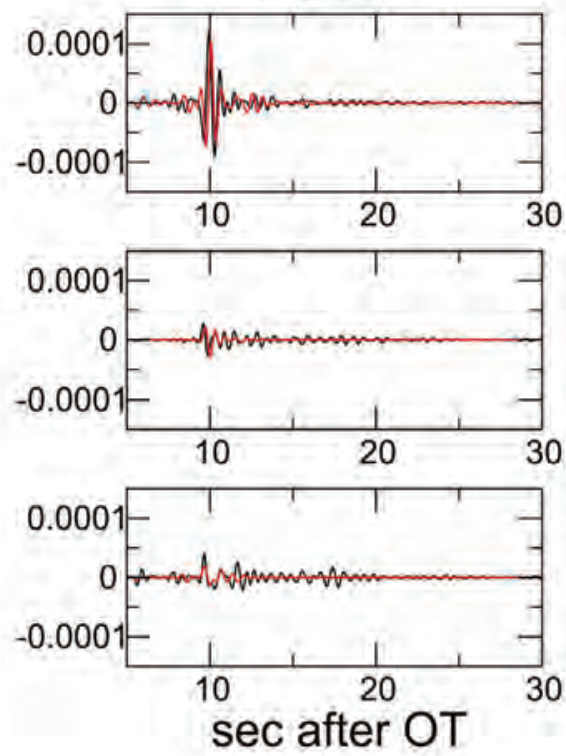

Figure 11. Observed (black) and synthetic (red) velocity waveforms at station HAWA for the Prosser earthquake. Left panel shows synthetics for the 3D model. Right panel shows synthetics for the 1D model.. 


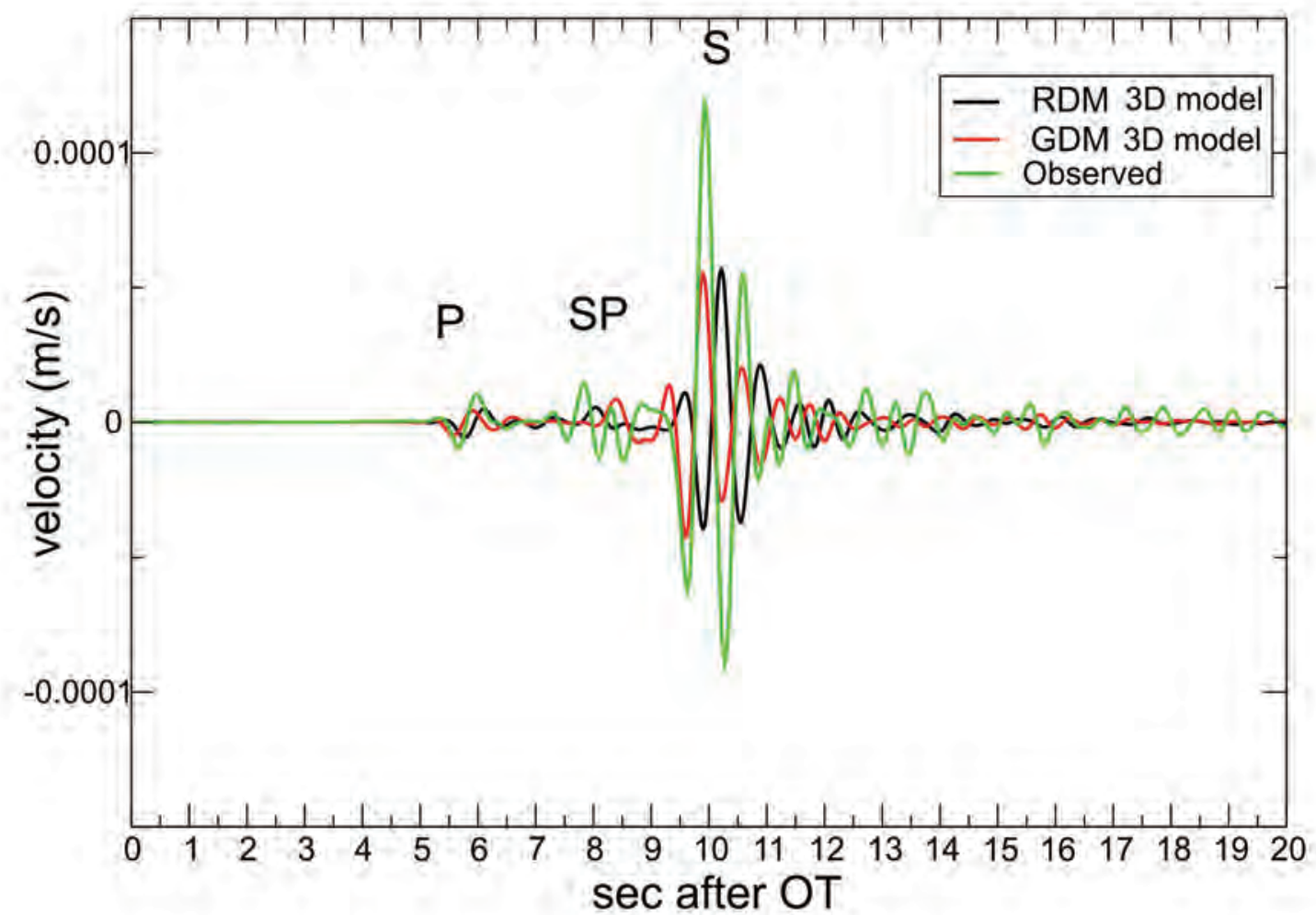

Figure 12. Observed and synthetics velocity waveforms (NS component) at station HAWA for the Prosser earthquake. Note arrival between P- and S-wave is inferred to be an S to P conversion (SP) at the top of basement, based on travel time calculations. 


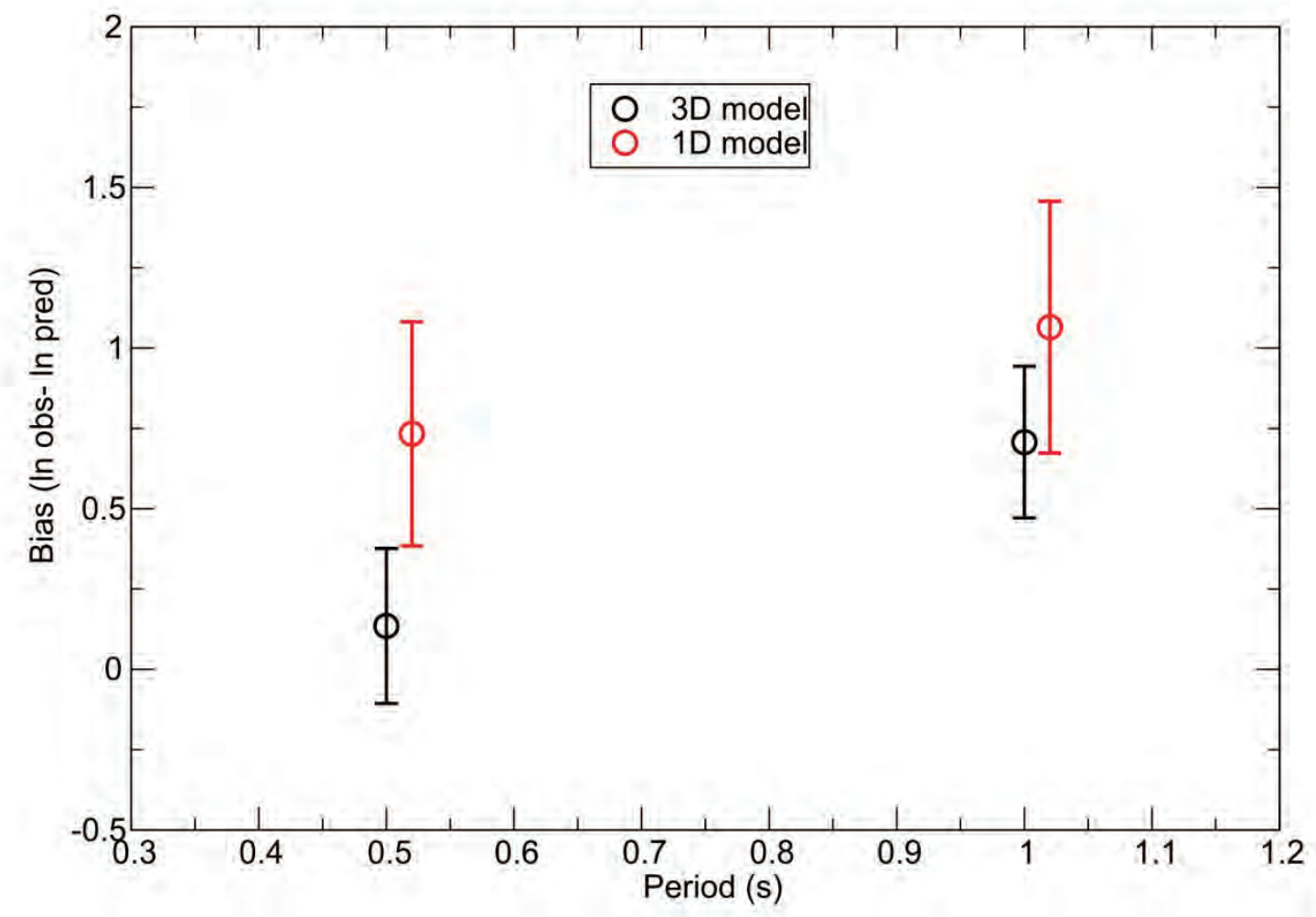

Figure 13. Bias and standard deviation of the spectral accelerations from the observed recordings at 0.5 and $1.0 \mathrm{~s}$ with respect to the spectral accelerations from the synthetics for the Prosser earthquakes (stations H3A, H4A, H2E, and LTH). Note that the bias is larger for the synthetics from the one-dimensional (1D) model than those from the three-dimensional (3D) model (refraction-derived model). 


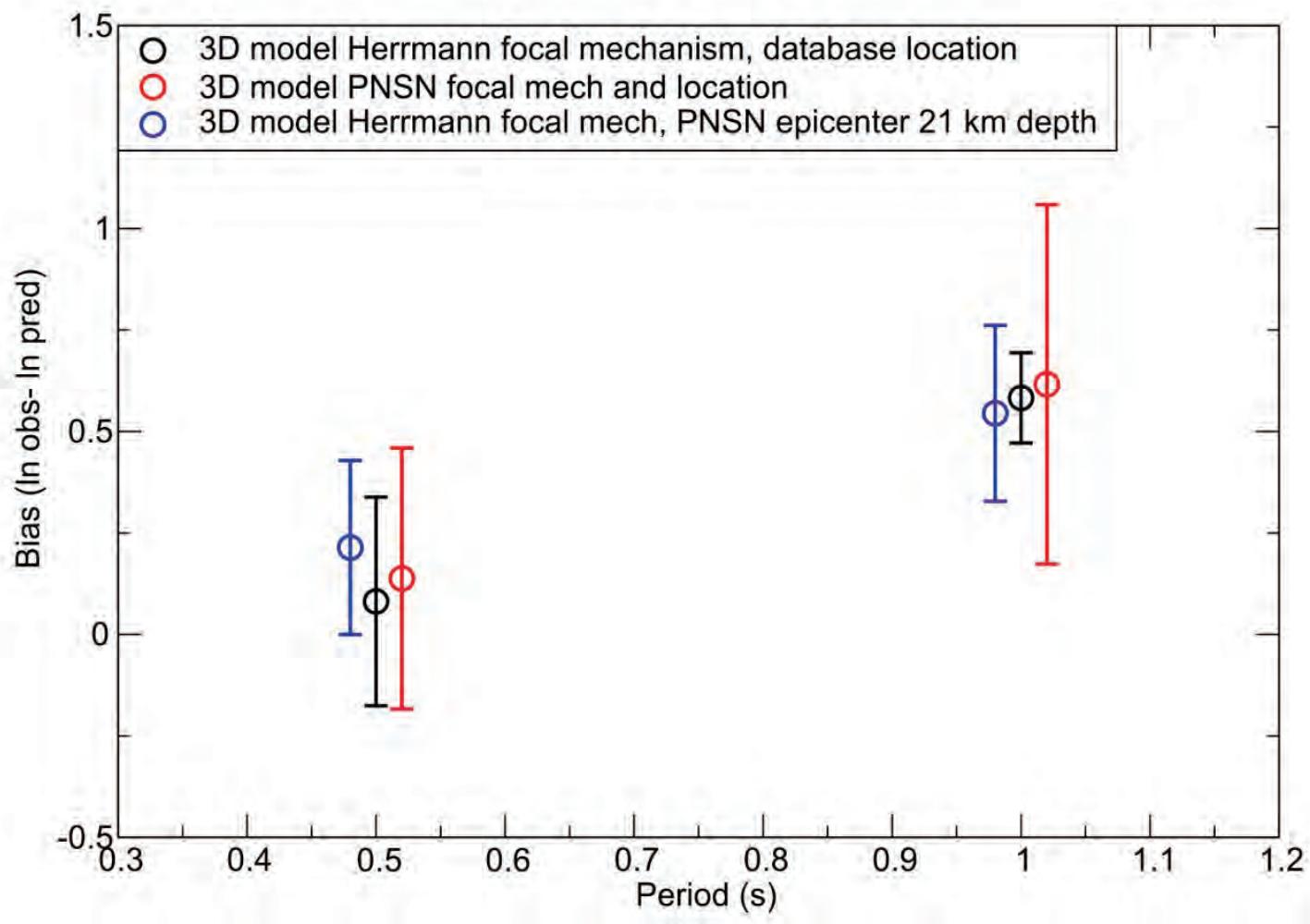

Figure 14. Bias and standard deviation of observed versus synthetic spectral accelerations for the Prosser earthquake. Different focal mechanisms and slightly different hypocenters were considered in threedimensional (3D) simulations for the same 3D velocity model (refraction-derived model). 


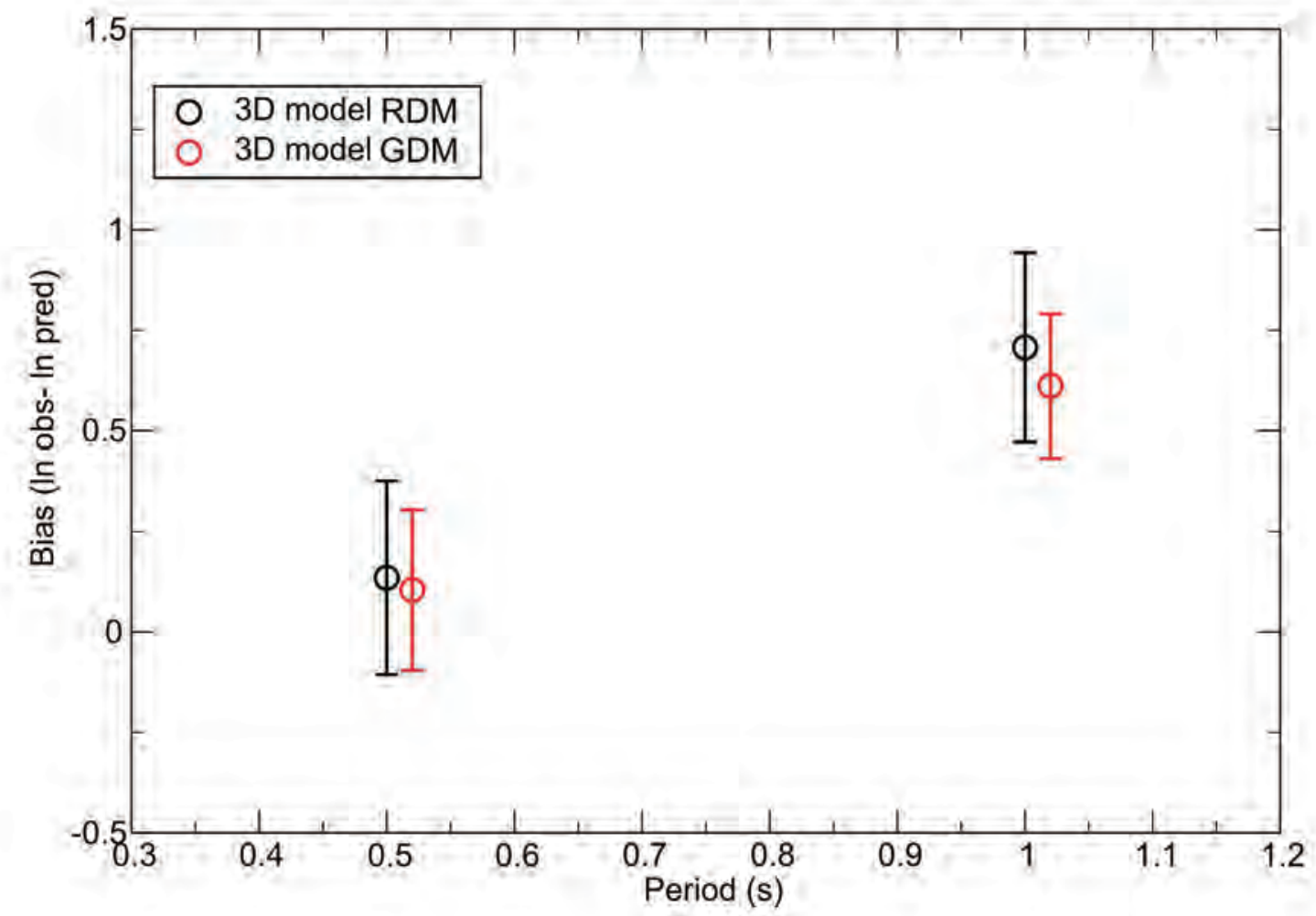

Figure 15. Bias and standard deviation of observed versus synthetic spectral accelerations for the Prosser earthquake using three-dimensional (3D) models with different depths to basement. 

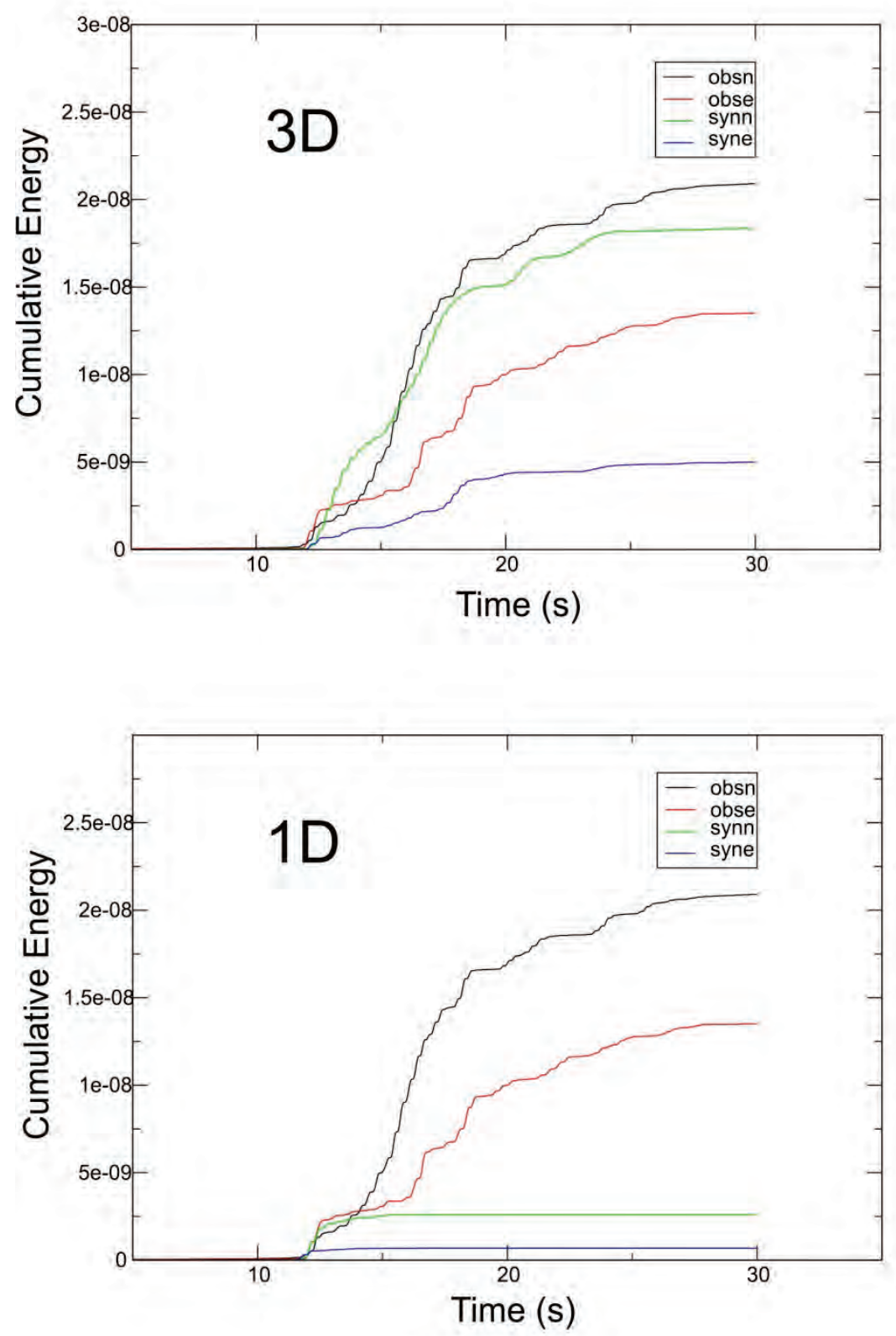

Figure 16. Cumulative energy at station $\mathrm{H} 4 \mathrm{~A}$ for Prosser earthquake plotted with respect to time after origin time for observed seismograms (black and red lines) compared to synthetics (green and blue lines) from three-dimensional (3D) (top) and one-dimensional (1D) (bottom) velocity models. Results are plotted for the east-west and north-south components. 


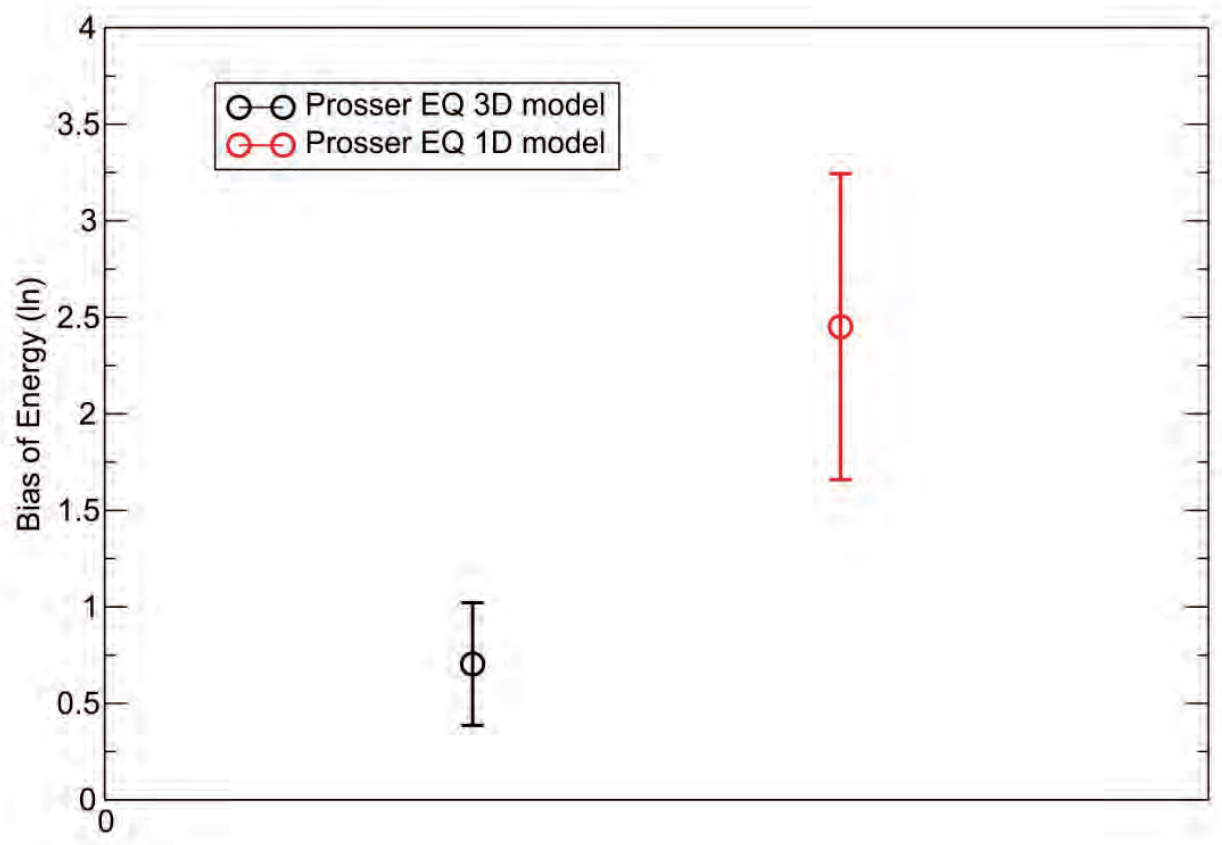

Figure 17. Bias and standard deviation of energy derived from observed seismograms compared with those from the three-dimensional (3D) and one-dimensional (1D) synthetics, for the Prosser earthquake (stations $\mathrm{H} 3 \mathrm{~A}, \mathrm{H} 4 \mathrm{~A}, \mathrm{H} 2 \mathrm{E}$, and LTH). 
H4A 3D
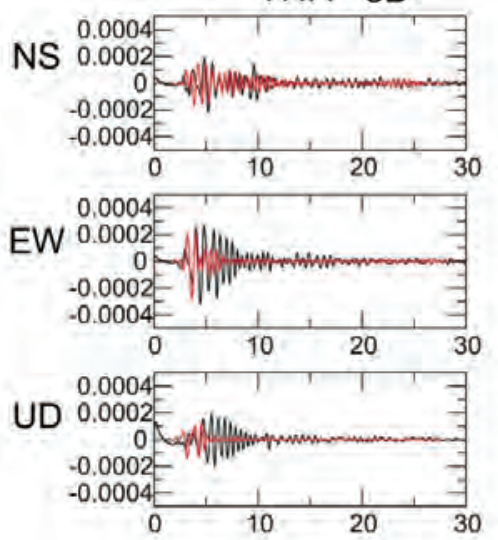

H2E 3D

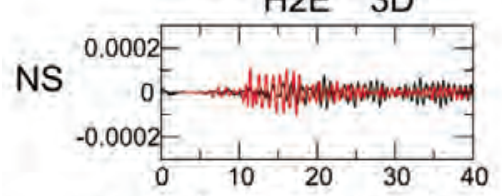

EW

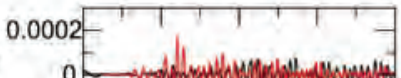

$-0.0002-$

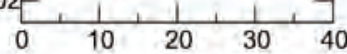

UD

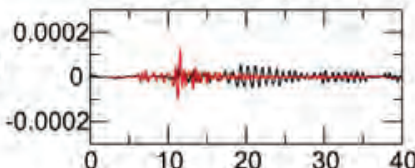

H2W 3D
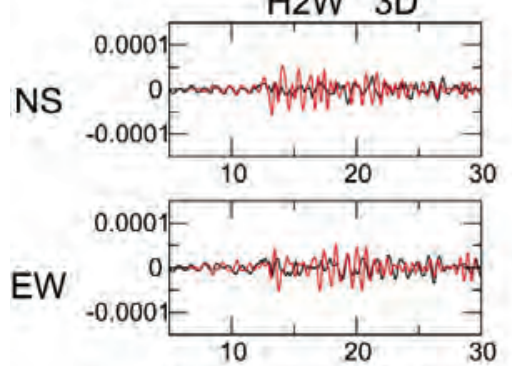

UD

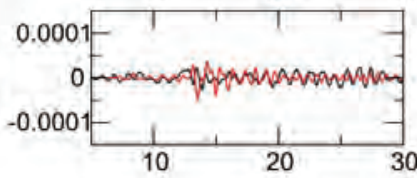

sec after OT
H4A 1D
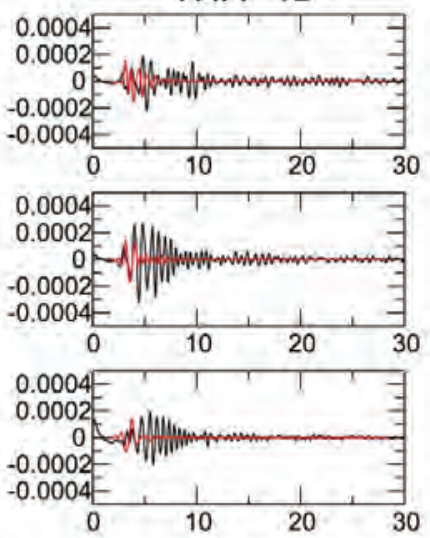

H2E 1D

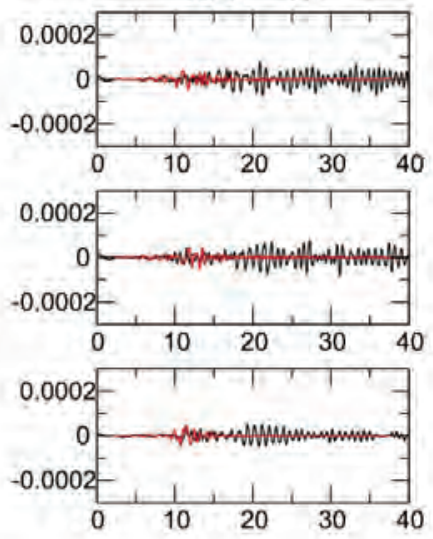

H2W 1D
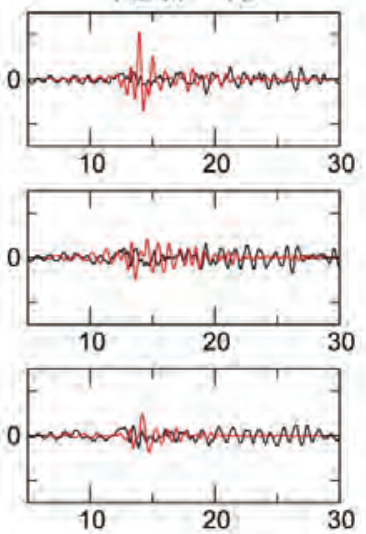

sec after OT

Figure 18. Observed (black) and synthetic (red) velocity waveforms for the September 2011 Wooded Island earthquake. Left panel shows synthetics for the 3D model. Right panel shows synthetics for the 1D model. 


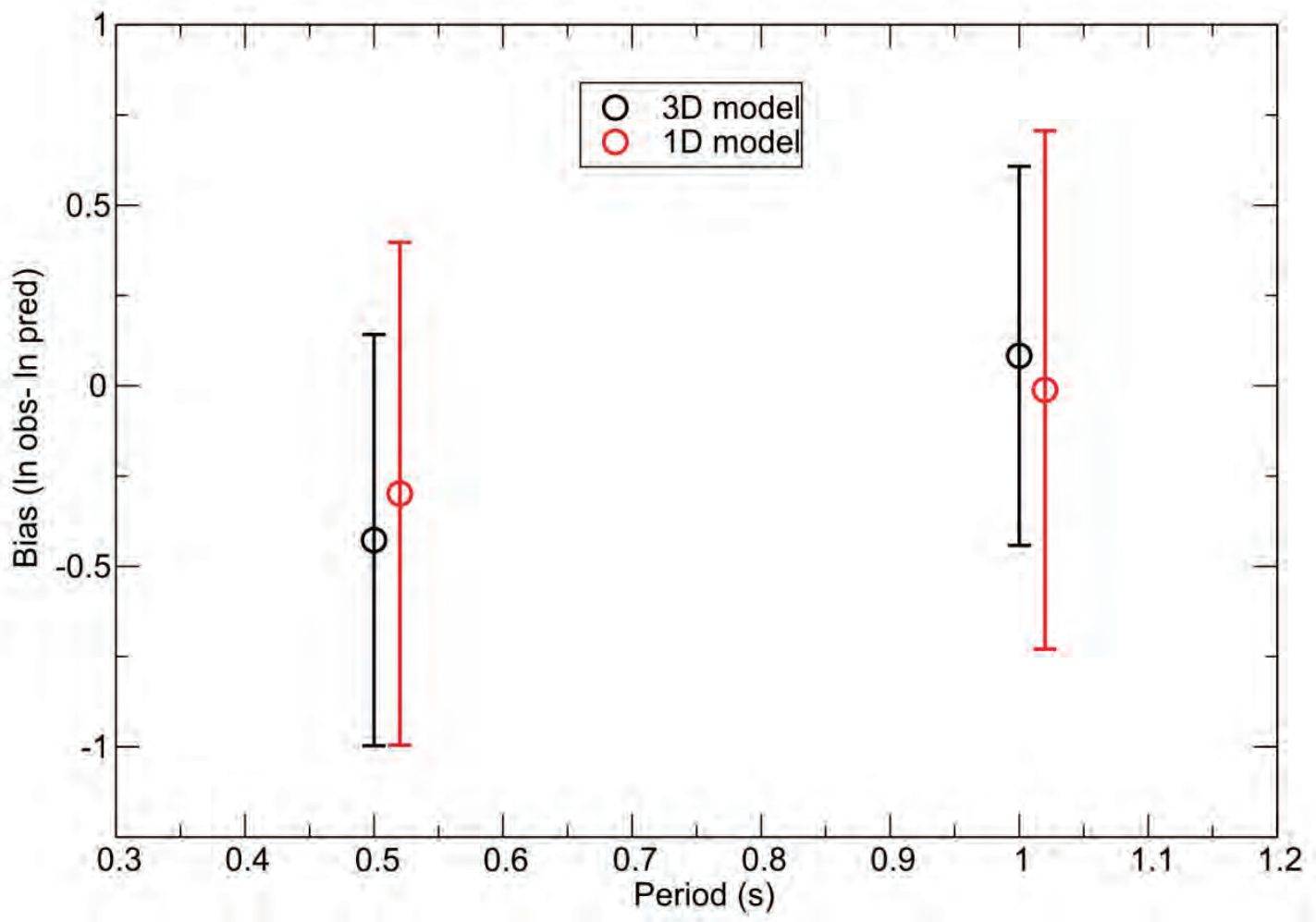

Figure 19. Bias and standard deviation of the observed and synthetics spectral accelerations for the September 2011 Wooded Island earthquake. 

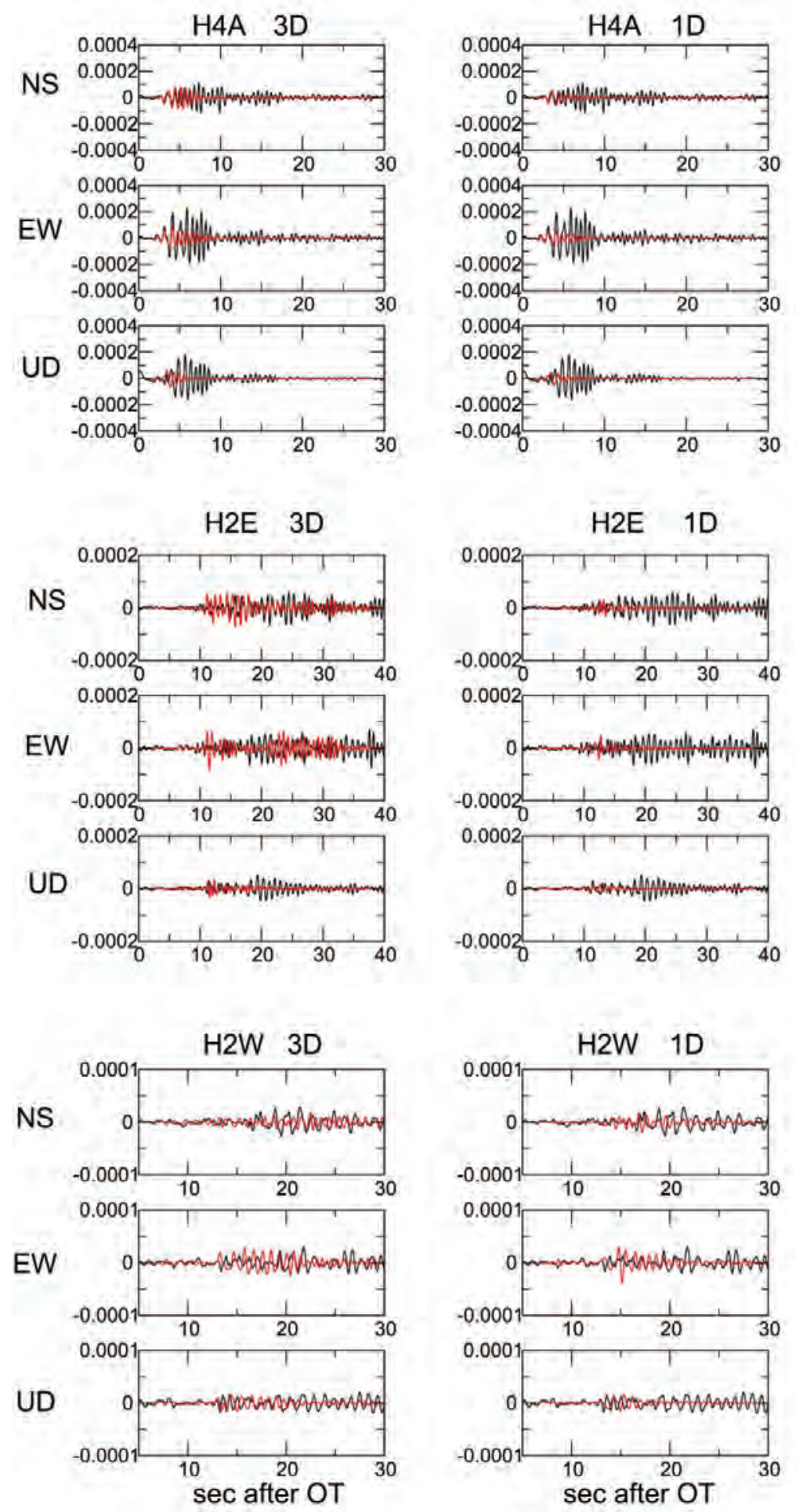

Figure 20. Observed (black) and synthetic (red) velocity waveforms for the October 2011 Wooded Island earthquake. Left panel is for the 3D model. Right panel is for the 1D model. NS, north-south; EW, eastwest; UD, up-down; OT, origin time. 


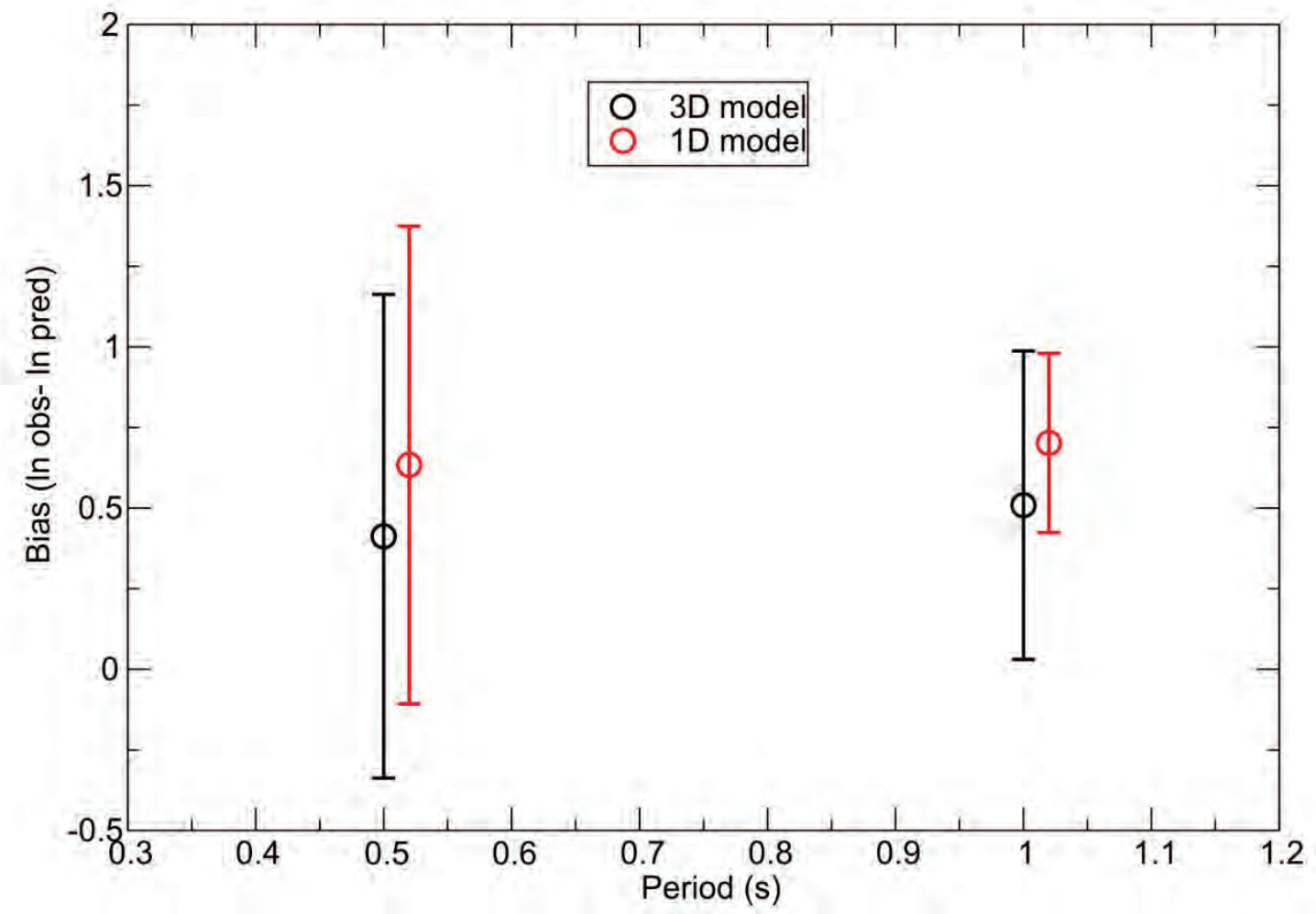

Figure 21. Bias and standard deviation of the observed and synthetic spectral accelerations for the October 2011 Wooded Island earthquake. 
3D

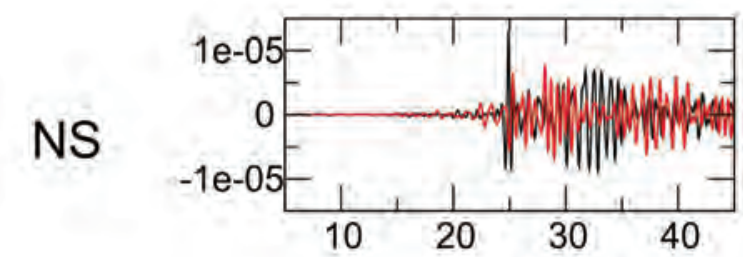

EW
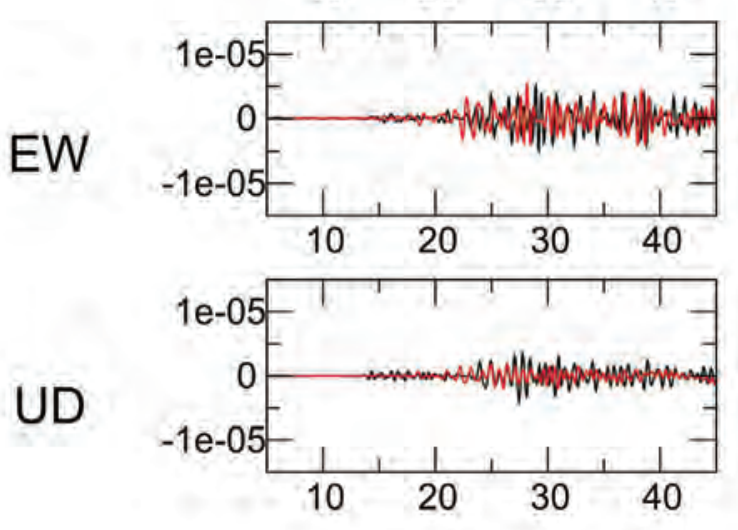

sec after OT
1D GDM
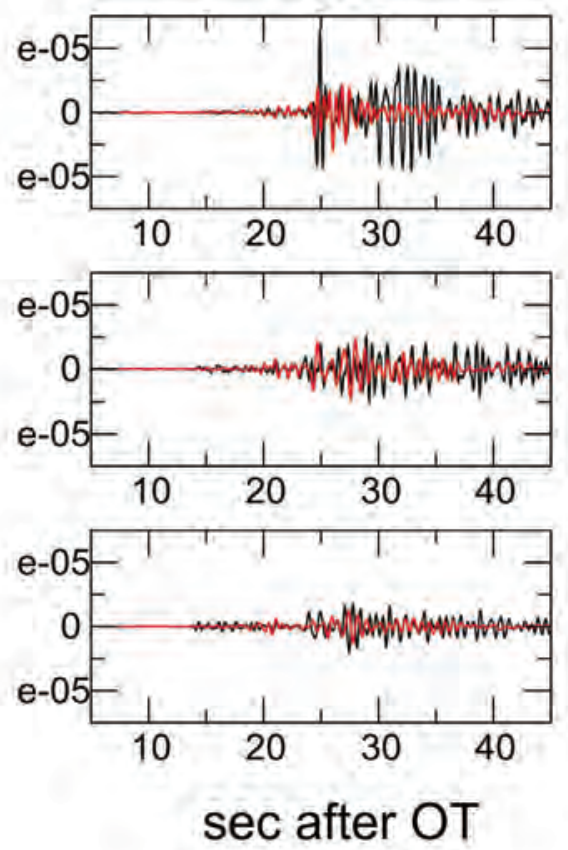

Figure 22. Observed (black) and synthetic (red) velocity waveforms at station LTH for the Walla Walla earthquake. Left panel shows synthetics for the 3D model. Right panel shows synthetics for the 1D model. 


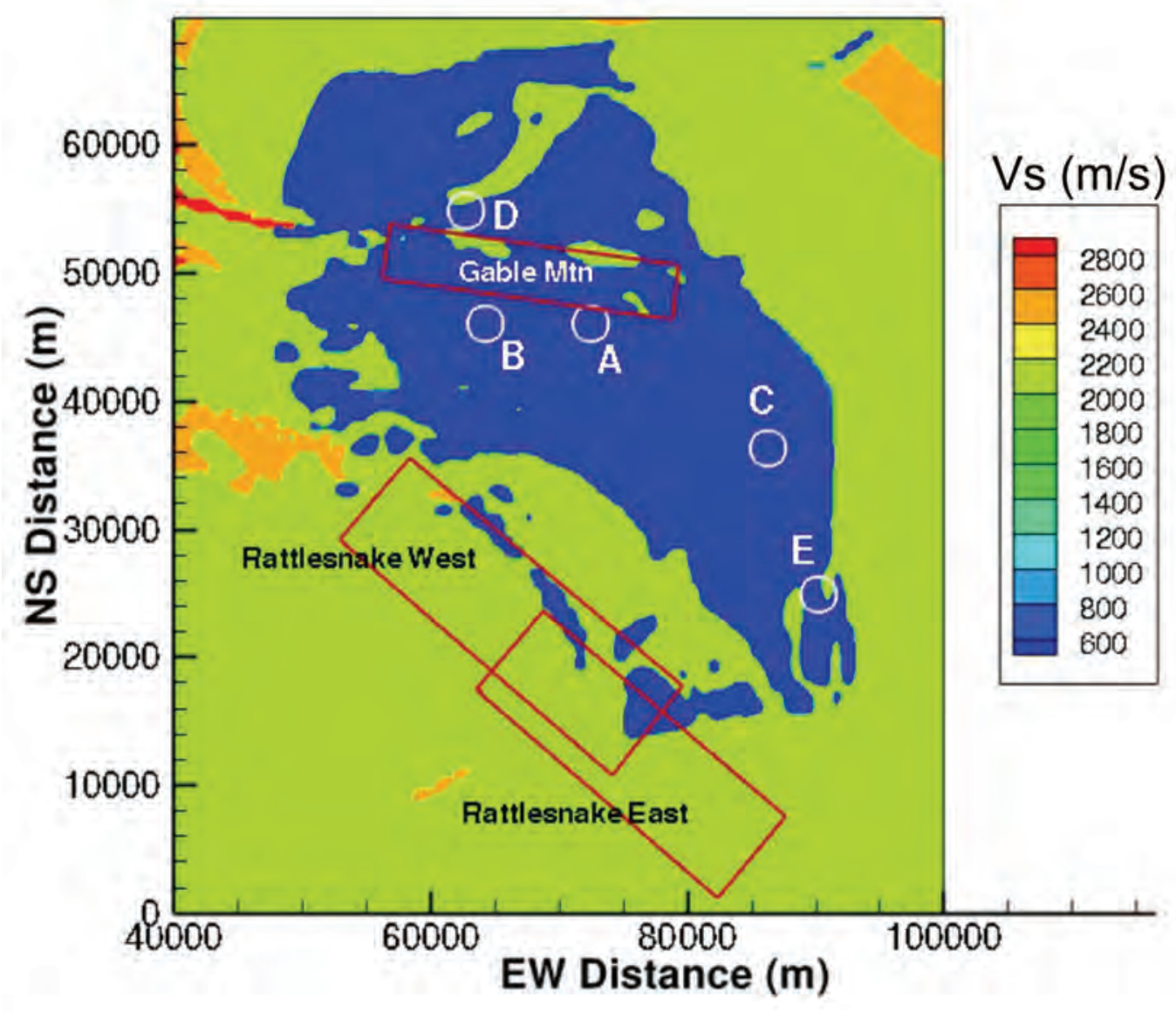

Figure 23. Map showing surficial S-wave velocity (Vs)(in meters per second) of three-dimensional model and surface projections (red rectangles) of rupture planes used in the simulations. Circles denote sites used in the probabilistic seismic hazard assessment and for the receivers in the simulations. A (200 East area and adjacent to the Waste Treatment Plant), B (200 West area), C (Columbia Generating Station), D (100 BC area), and E (300 area). 

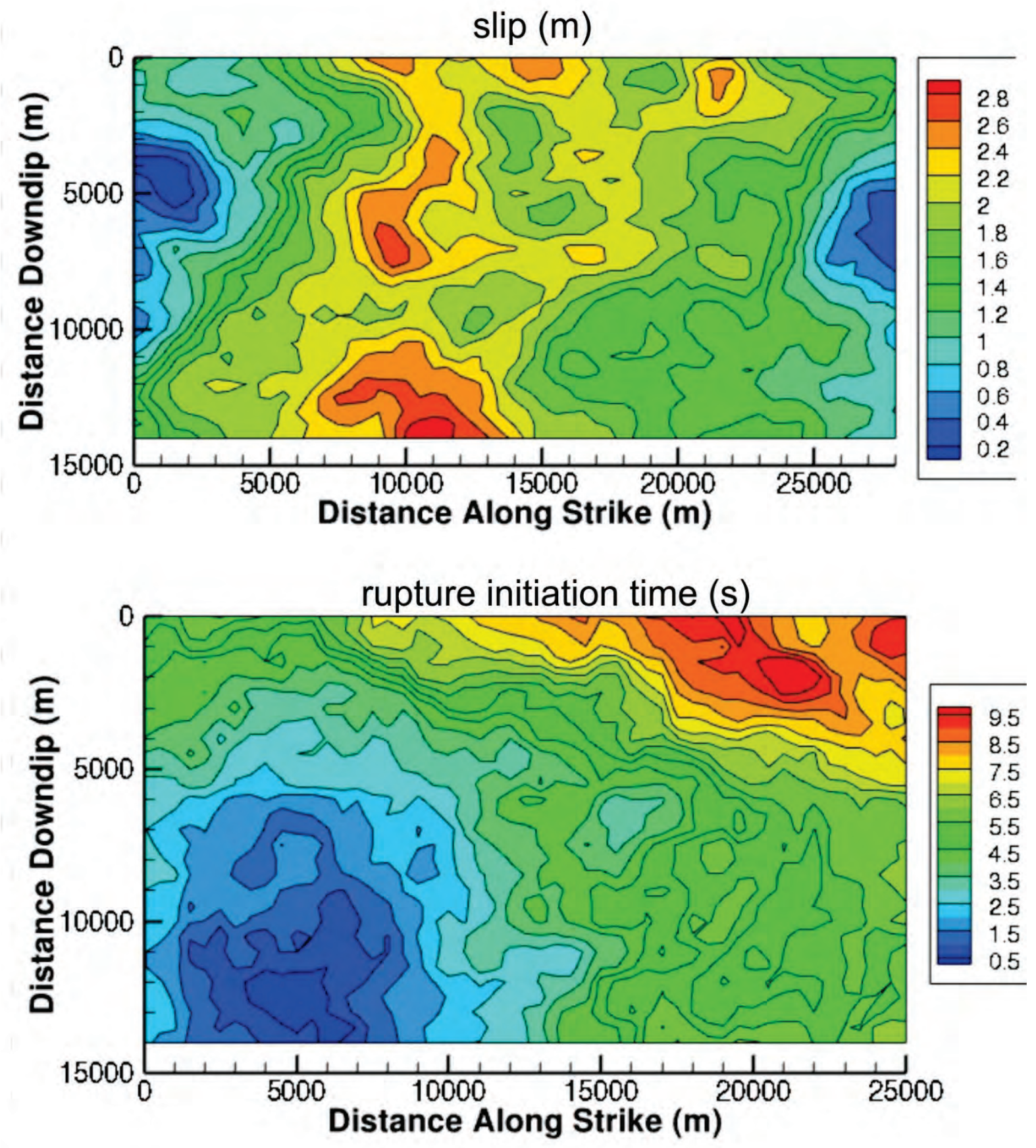

Figure 24. Final slip and rupture initiation times for one of the simulations for the Rattlesnake Hills West source. 

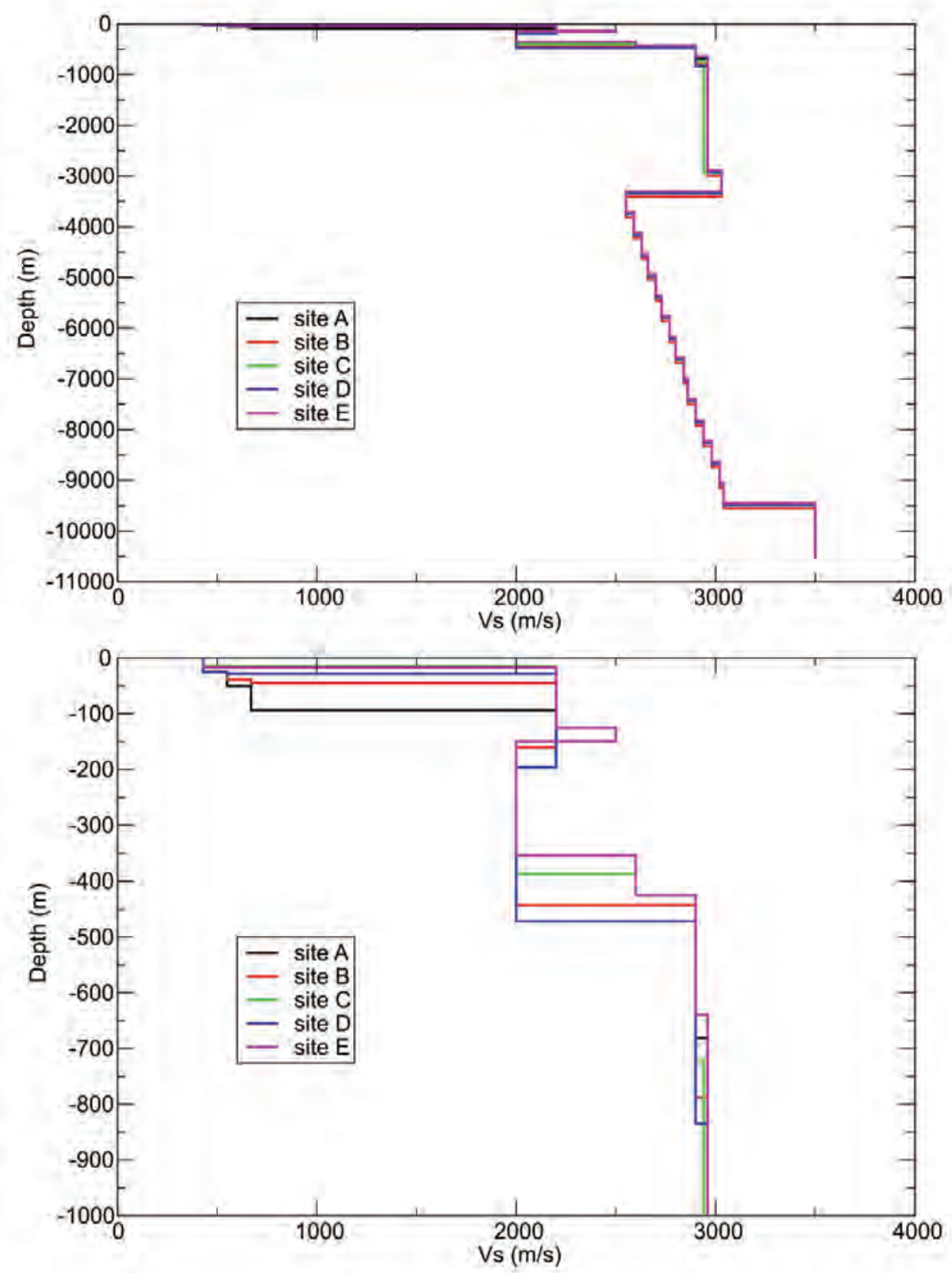

Figure 25. S-wave velocity (Vs) profiles used in the one-dimensional (1D) simulations for the Rattlesnake Hills West and Gable Mountain sources (bottom panel shows shallow portion). The thickness of the basalts and the depth to the top of basement vary somewhat for the Vs profiles used for the Rattlesnake Hills East and Cascadia 1D simulations (see text). 
A
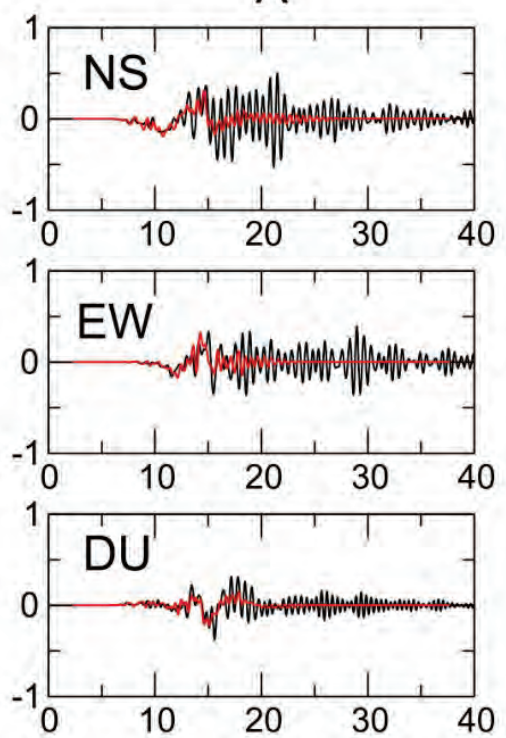

B
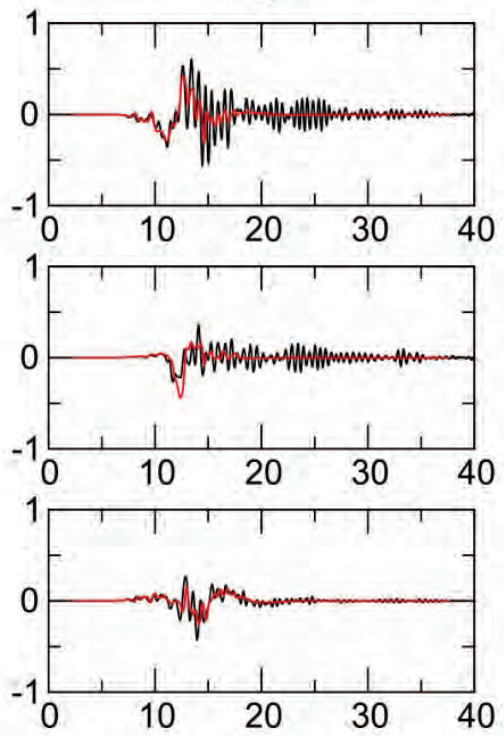

D
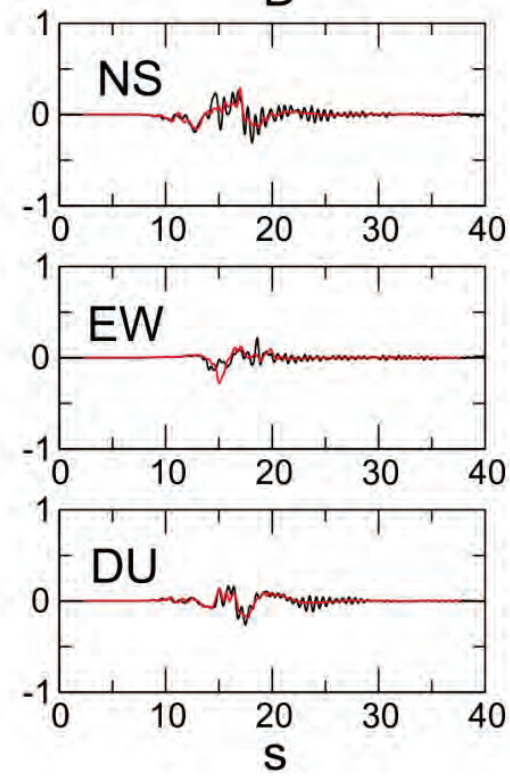
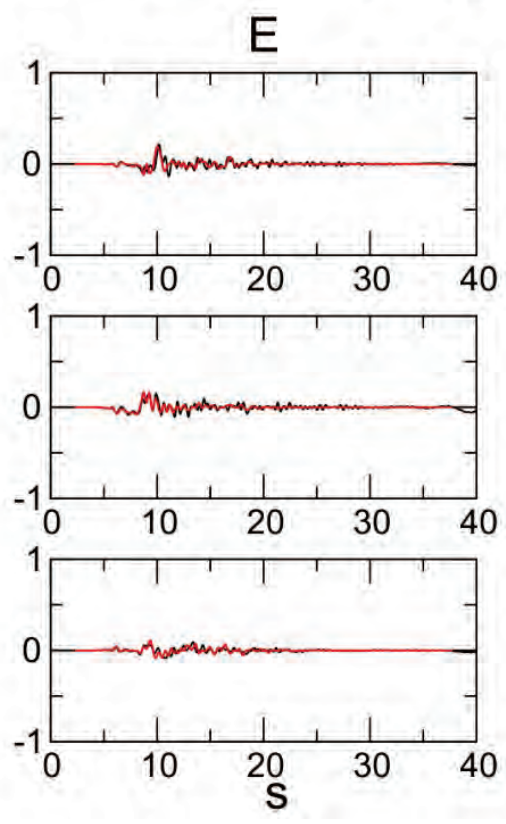

Figure 26. Velocity seismograms for one of the simulations of a magnitude 6.8 earthquake on the Rattlesnake Hills West source. Synthetics for three-dimensional model are in black, synthetics for onedimensional models are in red, and vertical scale is in meters per second. 

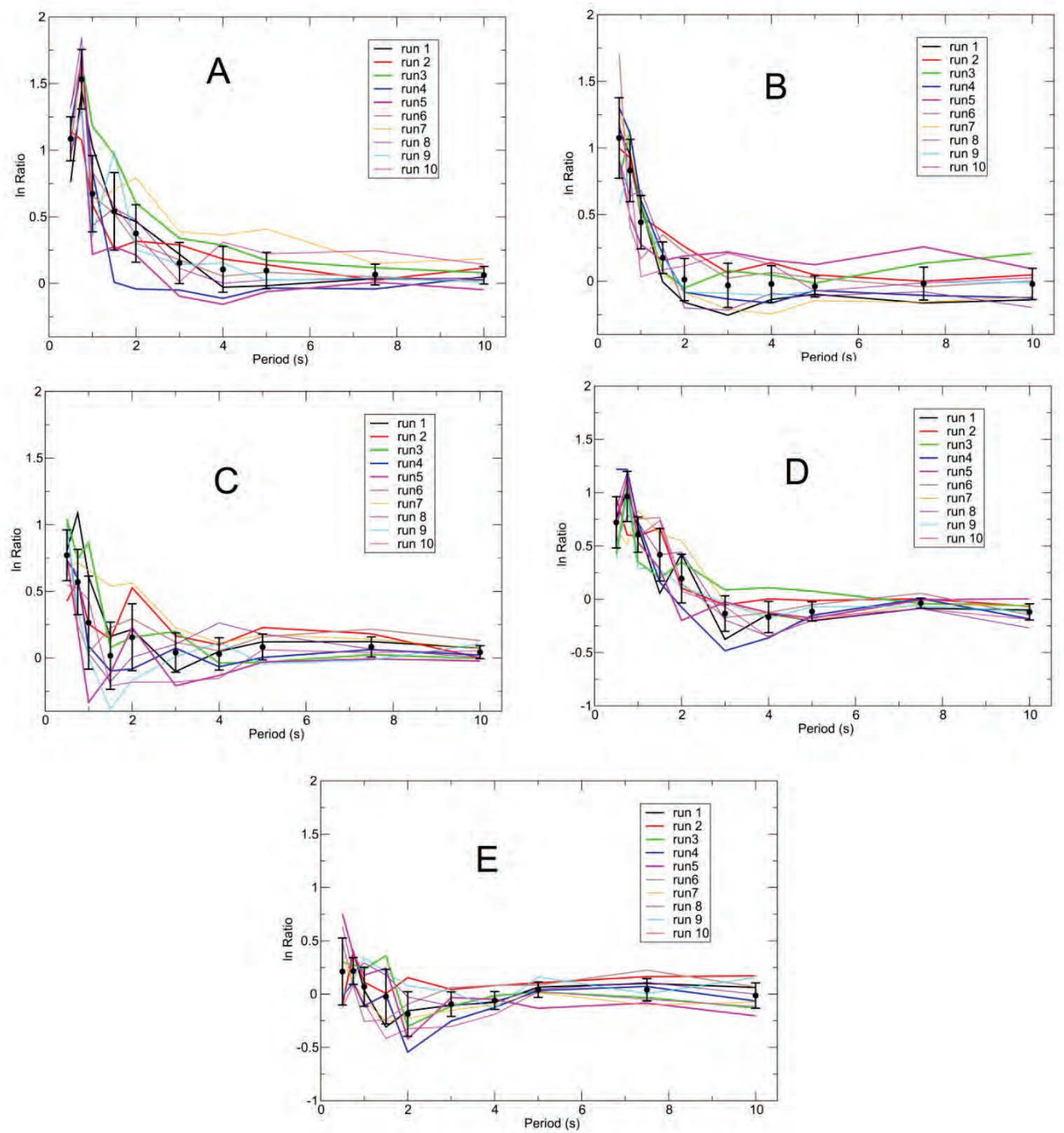

Figure 27. Natural logarithms of ratios of spectral accelerations between the three-dimensional (3D) and one-dimensional (1D) models for the magnitude 6.8 Rattlesnake Hills West source for the sites used for the probabilistic seismic hazard assessment. Each colored line represents the ratios for one rupture simulation. Positive values indicate that the spectral accelerations from the 3D model exceed those from the 1D model for that site. Dots with error bars are the mean and standard deviation, respectively, of the natural logarithms of the ratios for each period. 

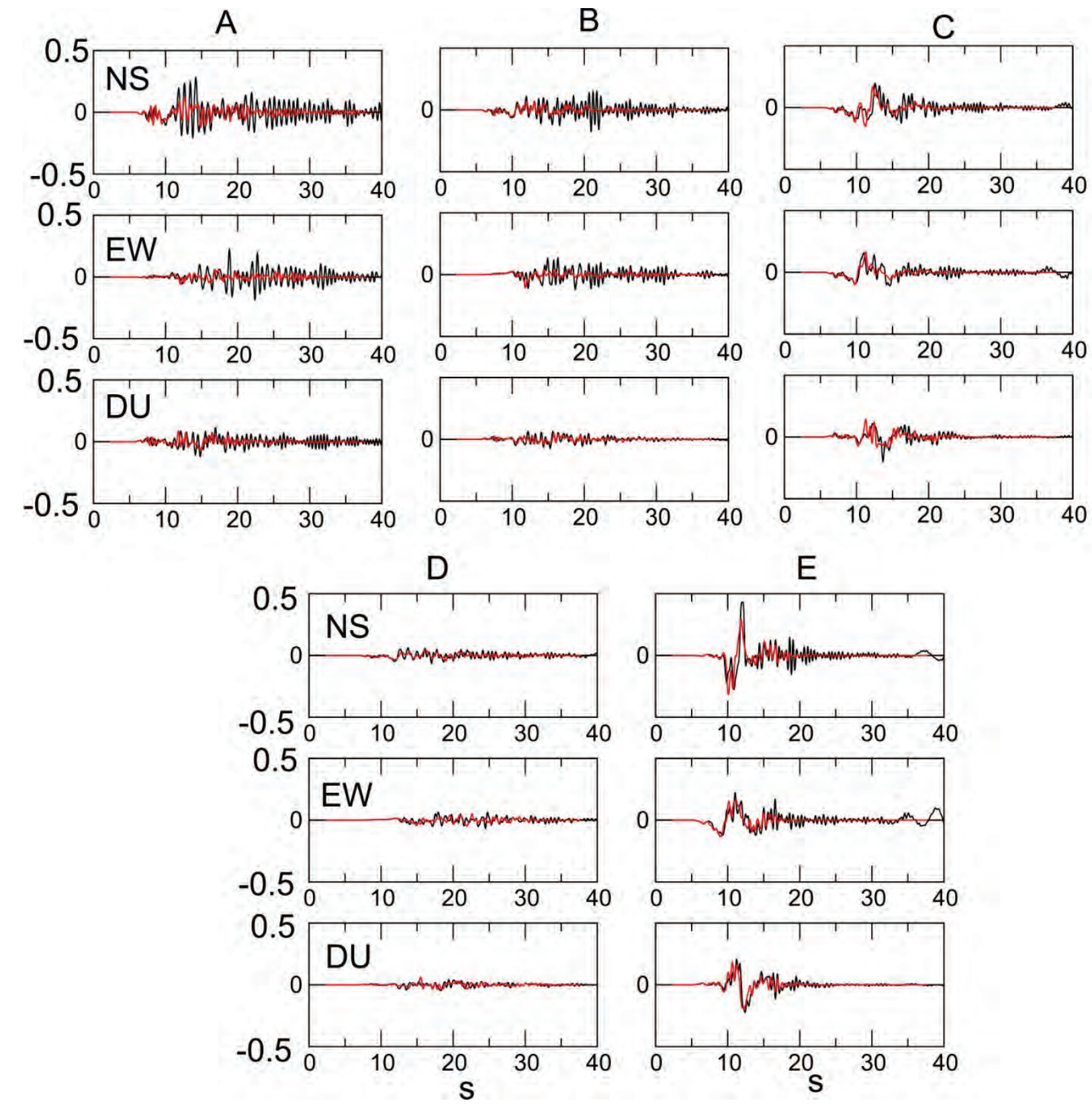

Figure 28. Velocity seismograms for one of the simulations of a M6.7 earthquake on the Rattlesnake Hills East source. Synthetics for three-dimensional model are in black, synthetics for one-dimensional models are in red, vertical scale is in meter per second. 

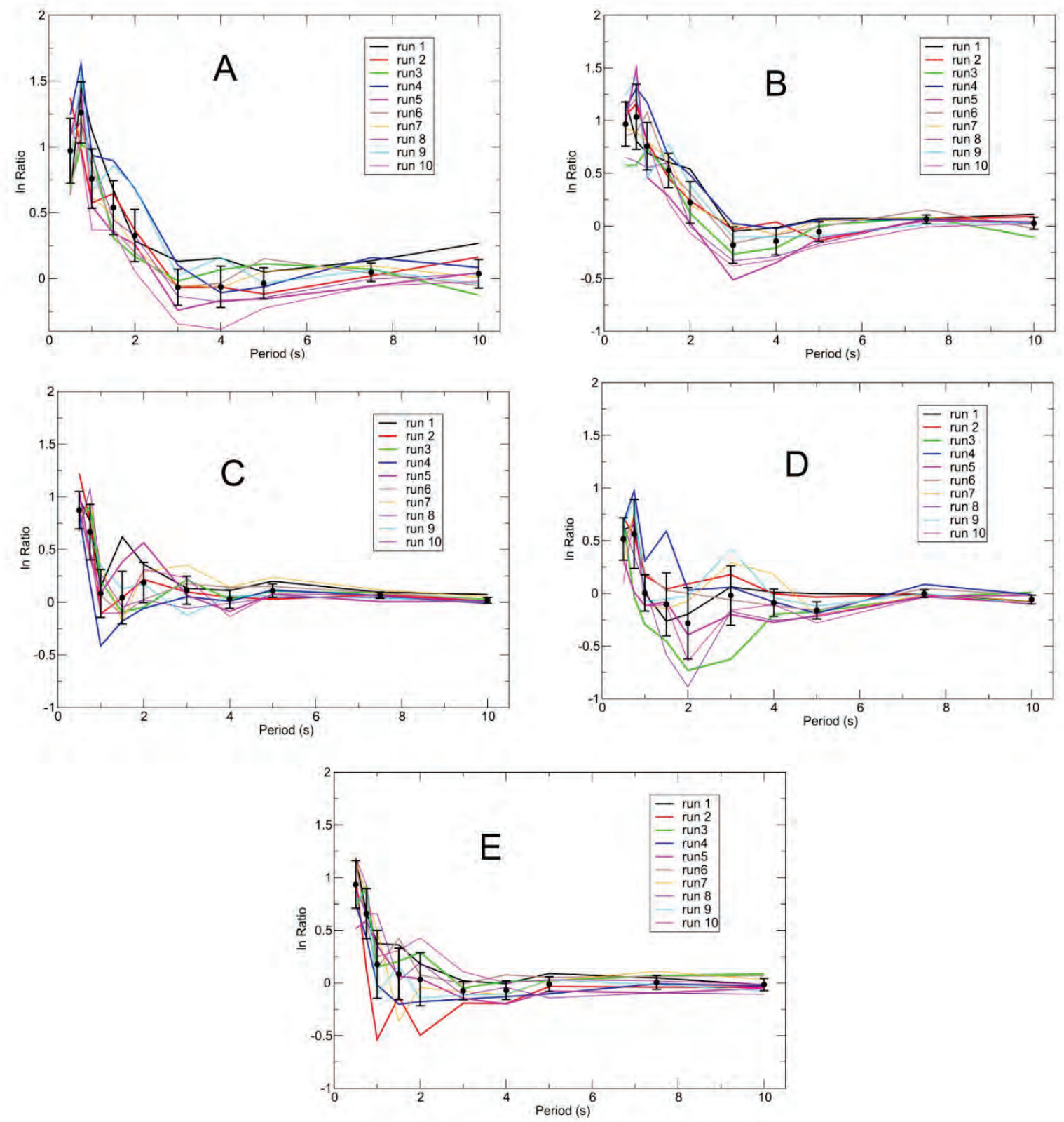

Figure 29. Natural logarithms of ratios of spectral accelerations between the three-dimensional and onedimensional models for the magnitude 6.7 Rattlesnake Hills East source for the sites used for the probabilistic seismic hazard assessment. 
A
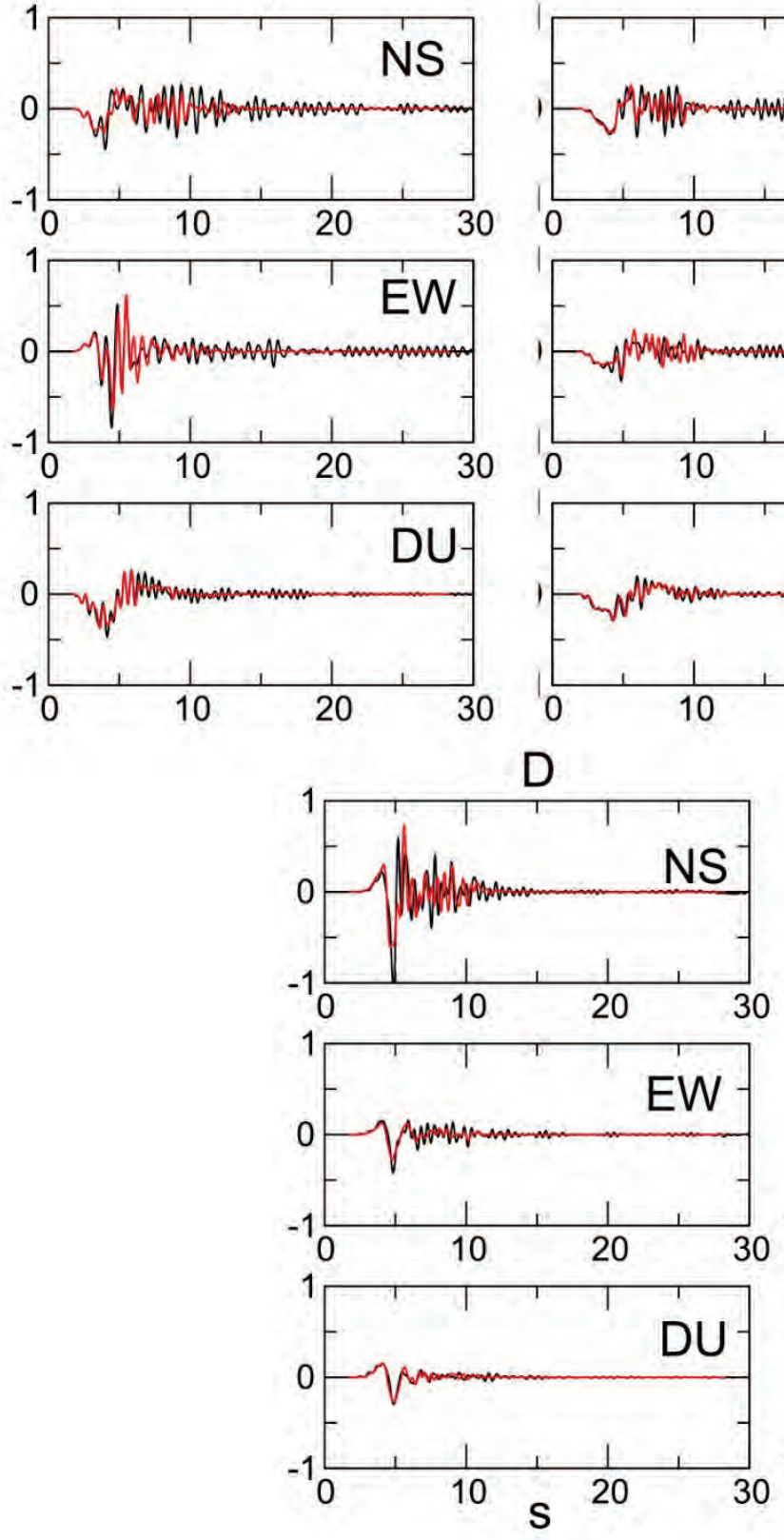

B
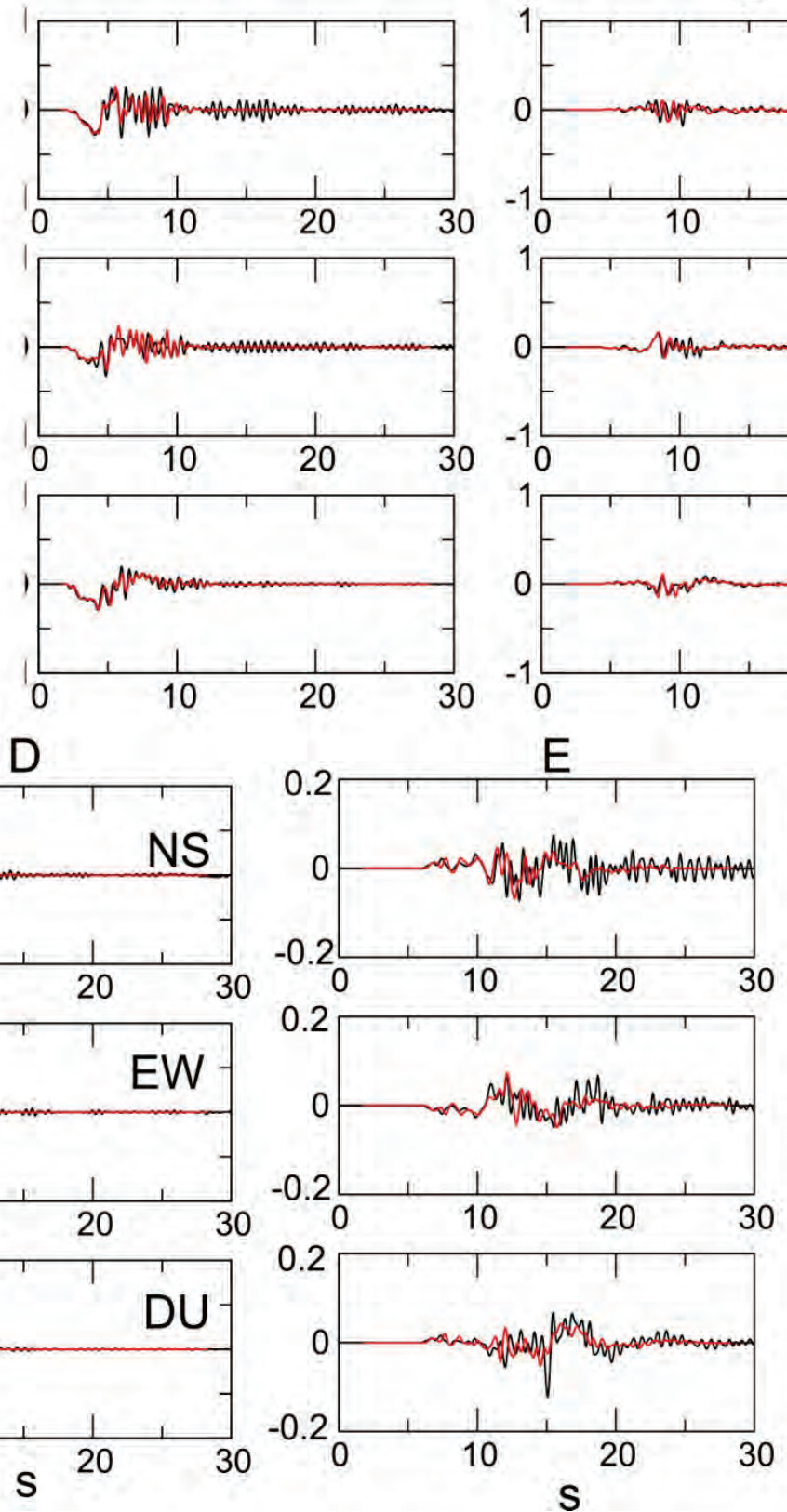

Figure 30. Velocity seismograms for one of the simulations of a magnitude 6.6 earthquake on the Gable Mountain fault. Synthetics for three-dimensional model are in black., synthetics for one-dimensional models are in red, and vertical scale is in meters per second. 

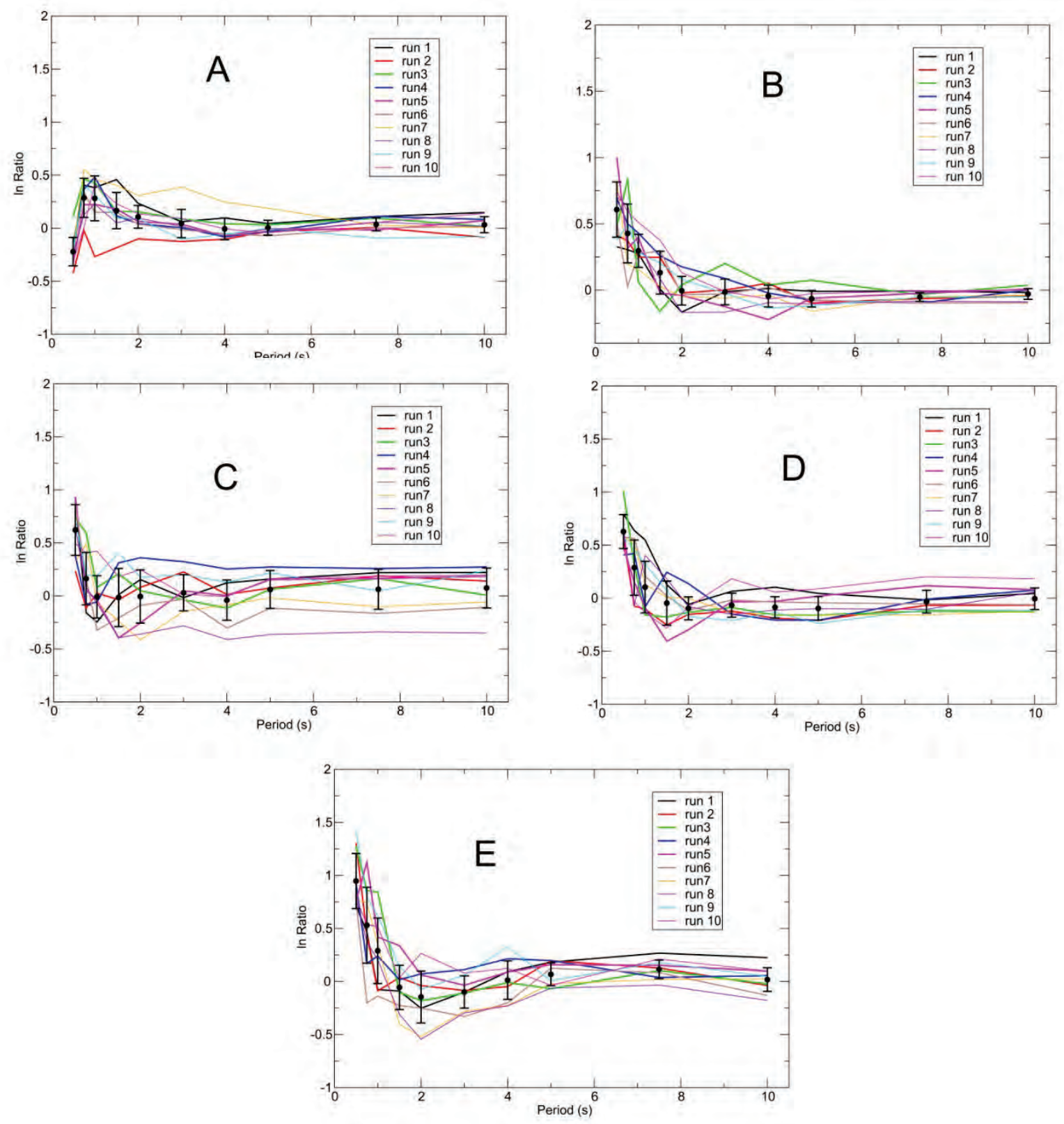

Figure 31. Natural logarithms of ratios of spectral accelerations between the three-dimensional and onedimensional models for the magnitude 6.6 Gable Mountain source for the sites used for the probabilistic seismic hazard assessment. 

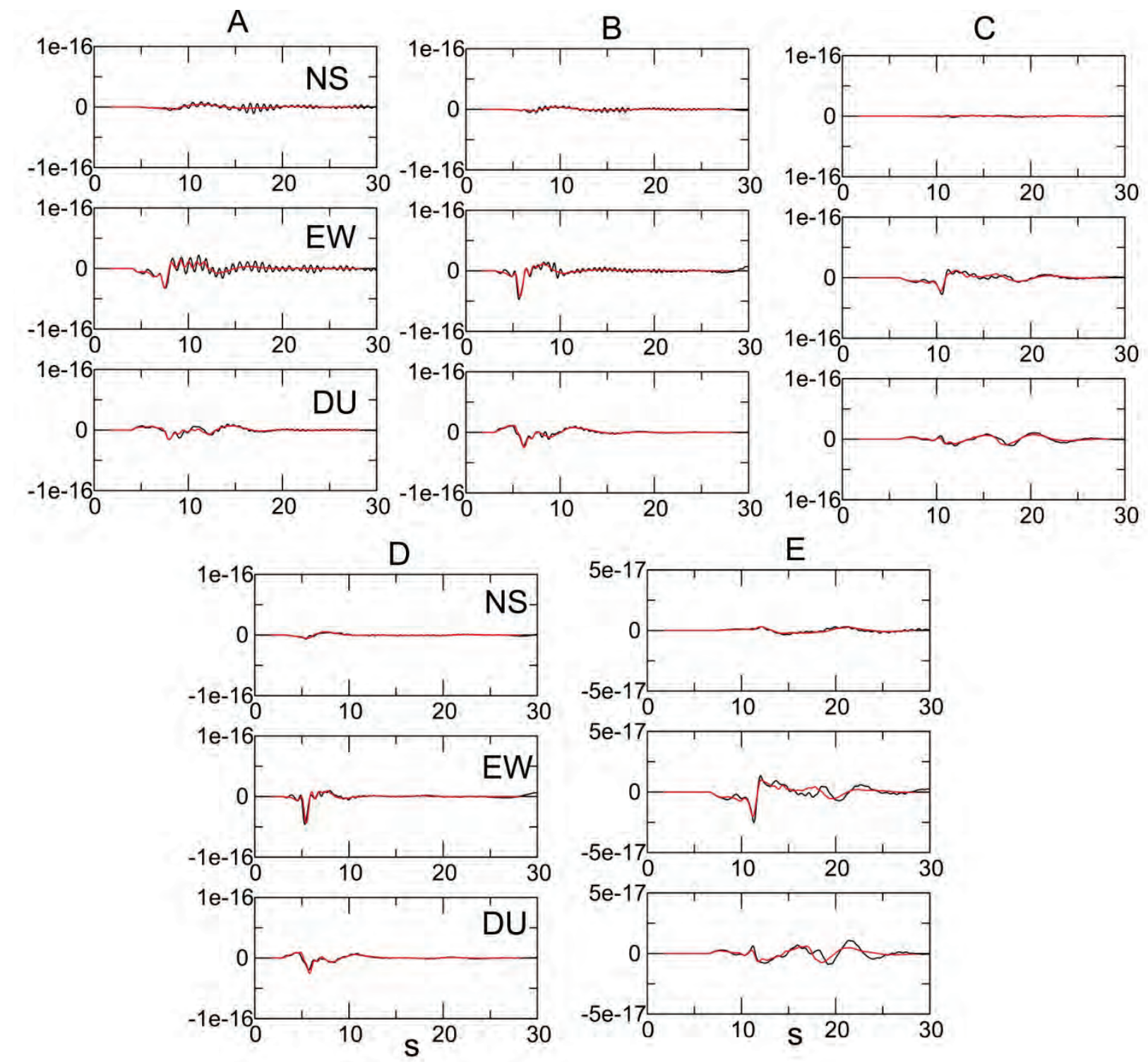

Figure 32. Velocity seismograms for simulation for Cascadia plane-wave source Synthetics for threedimensional model are in black, synthetics for one-dimensional models are in red, and vertical scale is in arbitrary units. 


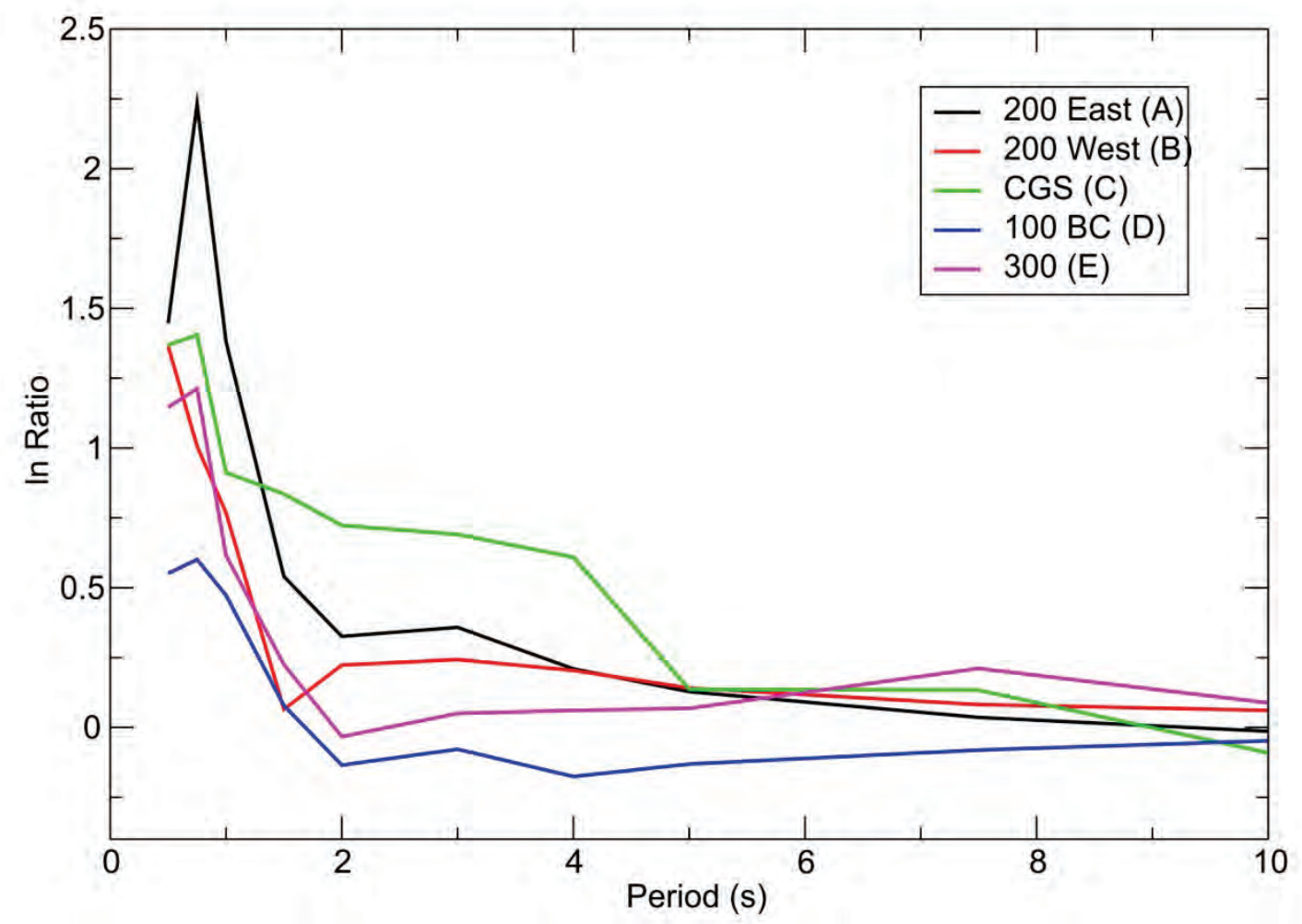

Figure 33. Natural logarithms of ratios of spectral accelerations from the three-dimensional model relative to those from the one-dimensional model at each site for the Cascadia plane wave source. 
Table 1. Source parameters of earthquakes simulated in this study.

[Source: Pacific Northwest Seismic Network (PNSN), unless otherwise indicated. Abbreviation: km, kilometer]

\begin{tabular}{|c|l|l|l|l|l|l|l|l|l|}
\hline & Yr Mo Day & $\begin{array}{c}\text { Hour } \\
\text { Min }\end{array}$ & $\begin{array}{c}\text { Latitude } \\
\left({ }^{\circ} \mathrm{N}\right)\end{array}$ & $\begin{array}{c}\text { Longitude } \\
\left({ }^{\circ} \mathrm{W}\right)\end{array}$ & $\begin{array}{c}\text { Depth } \\
(\mathrm{km})\end{array}$ & $\begin{array}{c}\text { Magni- } \\
\text { tude }\end{array}$ & Strike & Dip & Rake \\
\hline $\begin{array}{c}\text { Prosser } \\
\text { (PNSN focal } \\
\text { mechanism } \\
\text { and location) }\end{array}$ & 20080518 & $15: 20$ & 46.168 & 119.550 & 20.1 & $\mathrm{M}_{\mathrm{d}} 3.7$ & 60 & 45 & 80 \\
\hline $\begin{array}{c}\text { Prosser } \\
\text { (Herrmann } \\
\text { focal } \\
\text { mechanism } \\
\text { and database } \\
\text { location) }\end{array}$ & 20080518 & $15: 20$ & 46.156 & 119.528 & 18.0 & $\mathrm{M}_{\mathrm{w}} 3.27$ & 60 & 55 & 35 \\
\hline $\begin{array}{c}\text { Wooded } \\
\text { Island }\end{array}$ & 20110904 & $04: 13$ & 46.411 & 119.260 & 1.8 & $\mathrm{M}_{\mathrm{d}} 3.7$ & 340 & 45 & 130 \\
\hline $\begin{array}{c}\text { Wooded } \\
\text { Island }\end{array}$ & 20111015 & $06: 11$ & 46.408 & 119.262 & 1.4 & $\mathrm{M}_{\mathrm{d}} 3.4$ & 75 & 40 & 21 \\
\hline Walla Walla & 20061220 & $09: 43$ & 46.095 & 118.513 & 13.6 & $\mathrm{M}_{\mathrm{d}} 3.4$ & 120 & 55 & 110 \\
\hline
\end{tabular}

